\title{
Bioactive Ingredients in Chinese Herbal Medicines That Target Non-coding RNAs: Promising New Choices for Disease Treatment
}

\section{OPEN ACCESS}

Edited by:

Chandravanu Dash,

Meharry Medical College,

United States

Reviewed by:

Zijian Zhang,

Texas Tech University Health Sciences

Center El Paso, United States

Yong $\mathrm{Xu}$,

First Hospital of Shanxi Medical

University, China

*Correspondence:

Jun $L$

gamyylj@163.com

Jie Wang

wangjie0230@126.com

${ }^{\dagger}$ These authors have contributed equally to this work

Specialty section: This article was submitted to

Pharmacogenetics and

Pharmacogenomics,

a section of the journal

Frontiers in Pharmacology

Received: 13 January 2019

Accepted: 24 April 2019

Published: 21 May 2019

Citation:

Dong Y, Chen H, Gao J, Liu Y, Li J and Wang J (2019) Bioactive Ingredients in

Chinese Herbal Medicines That Target

Non-coding RNAs: Promising New

Choices for Disease Treatment.

Front. Pharmacol. 10:515.

doi: 10.3389/fphar.2019.00515

\author{
Yan Dong ${ }^{\dagger}$, Hengwen Chen ${ }^{\dagger}$, Jialiang Gao, Yongmei Liu, Jun Li* and Jie Wang* \\ Department of Cardiology, Guang'anmen Hospital, China Academy of Chinese Medical Sciences, Beijing, China
}

Chinese herbal medicines (CHMs) are widely used in China and have long been a powerful method to treat diseases in Chinese people. Bioactive ingredients are the main components extracted from herbs that have therapeutic properties. Since artemisinin was discovered to inhibit malaria by Nobel laureate Youyou Tu, extracts from natural plants, particularly bioactive ingredients, have aroused increasing attention among medical researchers. The bioactive ingredients of some CHMs have been found to target various non-coding RNA molecules (ncRNAs), especially miRNAs, IncRNAs, and circRNAs, which have emerged as new treatment targets in numerous diseases. Here we review the evidence that, by regulating the expression of ncRNAs, these ingredients exert protective effects, including pro-apoptosis, anti-proliferation and anti-migration, anti-inflammation, anti-atherosclerosis, anti-infection, anti-senescence, and suppression of structural remodeling. Consequently, they have potential as treatment agents in diseases such as cancer, cardiovascular disease, nervous system disease, inflammatory bowel disease, asthma, infectious diseases, and senescence-related diseases. Although research has been relatively limited and inadequate to date, the promising choices and new alternatives offered by bioactive ingredients for the treatment of the above diseases warrant serious investigation.

Keywords: bioactive ingredient, Chinese herbal medicine, traditional Chinese medicine, ncRNA, therapeutic target

\section{INTRODUCTION}

Chinese herbal medicines (CHMs) were the main treatment method used in ancient times by the Chinese to combat disease. As early as the Qin and Han Dynasty (around 221 BCE to 220 CE), Sheng Nong's Herbal Classic recorded 365 medicines. By the time of the Ming Dynasty (1368-1644), the number of CHMs listed in the book of Compendium of Materia Medica had increased to 1892. Most herbal medicines in such publications have been used constantly throughout medical history and are still applied in practice today. For example, according to Sheng Nong's Herbal Classic, Coptis chinensis Franch. was found to relieve abdominal pain and diarrhea and this herb is still widely used in China for the treatment of diarrhea or dysentery. Further, Panax notoginseng (Burk.) F. H. Chen, a traditional herb was initially used to stop bleeding, promote blood circulation and ease pain, was recorded in the Compendium of Materia Medica. It is now commonly used in cases of trauma and cardiovascular, and cerebrovascular diseases. A recent meta-analysis further demonstrated that several $P$. notoginseng preparations are beneficial for patients with unstable angina pectoris (Song et al., 2017). 
Despite the positive effects of CHMs, little is known about their effective constituents, bioactive ingredients, and mechanisms of action. Therefore, in addition to the clinical applications mentioned in classic texts, understanding the specific active ingredients and clarifying the mechanisms of action of these compounds would facilitate the improved application of CHMs. The discovery of the drug artemisinin best illustrates the importance of CHM to the world (Tu, 2016), inspiring the notion that, through study of their bioactive ingredients, CHMs can help people around the world to conquer life-threatening diseases.

Non-coding RNA molecules (ncRNAs), which mainly comprise miRNA, IncRNA, and circRNA, do not encode proteins; however, as the most abundant class of RNA (at least 90\%) (Sana et al., 2012), ncRNAs have important functions in gene regulation and are involved in pathological processes contributing to many diseases (Batista and Chang, 2013; Memczak et al., 2013; Zhang et al., 2018a), particularly cancer, and cardiovascular and nervous system diseases. Moreover, circRNA and lncRNA act as competitive endogenous RNAs (ceRNA), which are natural miRNA sponges that influence miRNA-induced gene silencing via miRNA response elements (Tay et al., 2014). Thus, complex regulatory networks exist, comprising circRNA, IncRNA, miRNA, and target genes. Unraveling of this complexity has laid the foundation for a comprehensive understanding of the pathology and treatment of diseases influenced by gene regulatory networks, rather than only core disease-related genes (Boyle et al., 2017). Excitingly, recent studies (Feng et al., 2015; Tian F. et al., 2017; Zhou Y. et al., 2017) have revealed that some miRNA, lncRNA, circRNA, and ceRNA crosstalk can be regulated by bioactive ingredients from CHMs, which often have multiple targets (Table 1). By influencing regulatory mechanisms, including pro-apoptosis (Feng et al., 2015), anti-proliferation and anti-migration (Liu T. et al., 2017), anti-inflammation (Fan et al., 2016), anti-atherosclerosis (Han et al., 2018), anti-infection (Liu et al., 2016), anti-senescence (Zhang J. et al., 2017), and suppression of structural remodeling (Liu L. et al., 2017), these ingredients exert protective functions in cancer, cardiovascular disease, nervous system disease, inflammatory bowel disease, asthma, infectious diseases, and senescence-related diseases.

\section{METHODOLOGY}

The bioactive ingredients of CHMs and their interactions with ncRNA targets are the subject of intensive and rapidly expanding research. In this study, we undertook a comprehensive review of this research. The PubMed database was searched using the terms: "(ncRNA) AND herbal medicine", "(((miRNA) OR lncRNA) OR circRNA) AND herbal medicine," "(((miRNA) OR lncRNA) OR circRNA) AND active ingredient," "(((miRNA) OR lncRNA) OR circRNA) AND Chinese herb," "(((miRNA) OR lncRNA) OR circRNA) AND natural agent," “(((miRNA) OR lncRNA) OR circRNA) AND natural compound," or
"(((miRNA) OR lncRNA) OR circRNA) AND traditional Chinese medicine."

In addition, the China National Knowledge Infrastructure (CNKI) was also searched with terms as follows: "FT = 'Chinese herbal medicine’ AND SU = 'ncRNA' NOT (TI = 'Review' OR TI = 'Progress' OR TI = 'Overview' OR TI = 'Current situation')," "FT $=$ 'Chinese herbal medicine' AND (SU = 'IncRNA' OR SU $=$ 'miRNA' OR SU = 'circRNA') NOT $(\mathrm{TI}=$ 'Review' OR TI = ' Progress' OR TI = 'Overview' OR TI = 'Current situation')," "FT $=$ 'Active ingredient' AND ( $\mathrm{SU}=$ 'IncRNA' OR SU = 'miRNA' OR SU = 'circRNA') NOT (TI = 'Review' OR TI = 'Progress' OR $\mathrm{TI}=$ 'Overview' OR TI = 'Current situation')," "FT = 'Natural compound' AND ( $\mathrm{SU}=$ 'IncRNA' OR SU = 'miRNA' OR SU $=$ 'circRNA') NOT $(\mathrm{TI}=$ 'Review' OR TI $=$ 'Progress' OR TI $=$ 'Overview' OR TI = 'Current situation')," "FT = 'Natural ingredient' AND (SU = 'IncRNA' OR SU = 'miRNA' OR SU = 'circRNA') NOT (TI = 'Review' OR TI = 'Progress' OR TI = 'Overview' OR TI = 'Current situation')," "FT = 'Traditional Chinese medicine extract' AND (SU = 'IncRNA' OR SU = 'miRNA' OR SU $=$ 'circRNA') NOT (TI = 'Review' OR TI = 'Progress' OR TI = 'Overview' OR TI = 'Current situation'),' or "FT $=$ 'Traditional Chinese medicine' AND (SU = 'IncRNA' OR SU $=$ 'miRNA' OR SU $=$ 'circRNA') NOT (TI = 'Review' OR TI $=$ 'Progress' OR TI = 'Overview' OR TI = 'Current situation')." "FT” means full text; "SU” means subject; “TI” means title. Articles included in "Guide to Core Journals of China," "Chinese Science Citation Database" and "Chemical Abstracts" simultaneously, were selected to ensure high quality of literature.

According to the above searching method, English and Chinese original articles related to bioactive ingredients of CHMs and any ncRNA (miRNA, lncRNA, or circRNA) were selected manually.

\section{PRO-APOPTOSIS EFFECTS OF CHMS}

Apoptosis is programmed cell death, which is a normal physiological process of cells. Imbalance of apoptosis is closely associated with various diseases, particularly cancer. Proteins that inhibit apoptosis are over-expressed in various cancers, and are considered to be related to tumorigenesis and chemotherapy resistance (Mohamed et al., 2017); therefore, the induction of apoptosis is a promising method for cancer management (Fulda and Vucic, 2012). Recently, several bioactive ingredients of CHMs have been reported to promote apoptosis by targeting miRNA, lncRNA, or ceRNA crosstalk, indicating their potential as complementary therapies for cancer.

\section{Berberine}

Berberine [BBR, 9,10-Dimethoxy-2,3-(methylenedioxy)7,8,13,13a-Tetrahydroberbinium; Chem. 1] is an isoquinoline alkaloid extracted from the roots of several species including: Coptis chinensis Franch., Berberis soulieana Schneid., Berberis poiretii Schneid., Berberis vernae Schneid., Berberis wilsoniae Hemsl., and Platycladus orientalis (Linn.) Franco. These herbs are considered to have antipyretic and detoxification effects, based on the theory of traditional Chinese medicine (TCM), and were mainly used to treat diseases of the digestive and 
TABLE 1 | Detailed information on bioactive ingredients targeting ncRNAs.

\begin{tabular}{|c|c|c|c|c|c|}
\hline No. & $\begin{array}{l}\text { Name of } \\
\text { ingredient }\end{array}$ & Original plant & ncRNA target & Gene/protein/pathway & Disease \\
\hline \multirow[t]{9}{*}{1} & Berberine & $\begin{array}{l}\text { Coptis chinensis Franch., } \\
\text { Berberis soulieana Schneid, } \\
\text { Berberis poiretii Schneid., } \\
\text { Berberis vernae Schneid, } \\
\text { Berberis wilsoniae Hemsl., } \\
\text { and Platycladus orientalis } \\
\text { (Linn.) Franco. }\end{array}$ & $\begin{array}{l}\text { miR-99a 125b (Feng et al., } \\
\text { 2015) } \\
\text { miR-21 (Luo et al., 2014) } \\
\text { miR-19a/92a (Yin et al., 2018) }\end{array}$ & $\begin{array}{l}\text { RAC1, NFKB1, MYC, JUN, and } \\
\text { CCND1 (Feng et al., 2015) } \\
\text { IL6/STAT3, PDCD4 (Luo et al., } \\
\text { 2014) } \\
\text { P53 signaling pathway (Luo } \\
\text { et al., 2014) } \\
\text { P53, ERB, and MAPK signaling } \\
\text { pathways (Feng et al., 2015) }\end{array}$ & $\begin{array}{l}\text { Multiple myeloma (Luo et al., } \\
\text { 2014; Feng et al., 2015; Yin } \\
\text { et al., 2018) }\end{array}$ \\
\hline & & & miR-23a (Wang N. et al., 2014) & $\begin{array}{l}\text { NEK6, P53, P21, GADD45 } \alpha \\
\text { (Wang N. et al., 2014) }\end{array}$ & $\begin{array}{l}\text { Hepatocellular carcinoma (Wang } \\
\text { N. et al., 2014) }\end{array}$ \\
\hline & & & $\begin{array}{l}\text { miR-152 } \\
\text { miR-429 } \\
\text { miR-29a (Huang et al., 2017) } \\
\text { miR-296-5p (Su et al., 2015) }\end{array}$ & $\begin{array}{l}\text { DNMT1, DNMT3A, DNMT3B, } \\
\text { CDK4 } \\
\text { (Su et al., 2015; Huang et al., } \\
\text { 2017) } \\
\text { Pin1- } \beta \text {-catenin-cyclin D1 } \\
\text { signaling pathway (Su et al., } \\
2015 \text { ) }\end{array}$ & $\begin{array}{l}\text { Colorectal cancer (Su et al., } \\
\text { 2015; Huang et al., 2017) }\end{array}$ \\
\hline & & & $\begin{array}{l}\text { miR-34a } \\
\text { miR-154 } \\
\text { miR-26a } \\
\text { miR-124 (Yang L. H. et al., 2016) }\end{array}$ & $\begin{array}{l}\text { CDK4, CyclinD1, CyclinE, CDK2 } \\
\text { (Yang L. H. et al., 2016) }\end{array}$ & $\begin{array}{l}\text { Melanoma (Yang L. H. et al., } \\
\text { 2016) }\end{array}$ \\
\hline & & & miR-93 (Chen et al., 2015) & $\begin{array}{l}\text { miR-93/PTEN/AKT signaling } \\
\text { pathway (Chen et al., 2015) }\end{array}$ & $\begin{array}{l}\text { Ovarian cancer (Chen et al., } \\
\text { 2015) }\end{array}$ \\
\hline & & & miR-203 (You et al., 2016) & BCL-w (You et al., 2016) & Gastric cancer (You et al., 2016) \\
\hline & & & $\begin{array}{l}\text { miR-27a miR-27b (Wu et al., } \\
\text { 2016) }\end{array}$ & PPAR- $\gamma$ (Wu et al., 2016) & Obesity (Wu et al., 2016) \\
\hline & & & $\begin{array}{l}\text { IncRNA MRAK052686 (Yuan } \\
\text { et al., 2015) }\end{array}$ & NRF2 (Yuan et al., 2015) & $\begin{array}{l}\text { Steatotic liver (Yuan et al., 2015; } \\
\text { Li C. H. et al., 2018) }\end{array}$ \\
\hline & & & miR-373 (Li C. H. et al., 2018) & $\begin{array}{l}\text { EGR1, AKT1 } \\
\text { AKT-mTOR-S6K signaling } \\
\text { pathway (Li C. H. et al., 2018) }\end{array}$ & \\
\hline \multirow{3}{*}{3} & & & 227 miRNAs (Reno et al., 2015) & $\begin{array}{l}\text { Focal adhesion kinase (Reno } \\
\text { et al., 2015) }\end{array}$ & Lung cancer (Reno et al., 2015) \\
\hline & & & $\begin{array}{l}\text { miR-17-92 } \\
\text { miR-106b-25 (Li S. G. et al., } \\
\text { 2018) }\end{array}$ & $\begin{array}{l}\text { c-MYC, BIM, PTEN, and P21 (Li } \\
\text { S. G. et al., 2018) }\end{array}$ & $\begin{array}{l}\text { Hepatocellular carcinoma (Li S. } \\
\text { G. et al., 2018) }\end{array}$ \\
\hline & & & $\begin{array}{l}\text { IncRNA THOR (Wang et al., } \\
\text { 2019) }\end{array}$ & $\begin{array}{l}\text { IGF2BP1, Myc, IGF2, and Gli1 } \\
\text { (Wang et al., 2019) }\end{array}$ & $\begin{array}{l}\text { Nasopharyngeal carcinoma } \\
\text { (Wang et al., 2019) }\end{array}$ \\
\hline 4 & Ailanthone & $\begin{array}{l}\text { Ailanthus altissima (Mill.) } \\
\text { Swingle }\end{array}$ & miR-21 (Yang P. et al., 2018) & $\begin{array}{l}\text { caspase 3, caspase 9, Beclin-1, } \\
\text { LC3-II, p62, and cyclin D1 } \\
\text { Ras/Raf/MEK/ERK and mTOR } \\
\text { pathways (Yang P. et al., 2018) }\end{array}$ & $\begin{array}{l}\text { Vestibular schwannomas (Yang } \\
\text { P. et al., 2018) }\end{array}$ \\
\hline \multirow[t]{2}{*}{5} & $\begin{array}{l}\text { Cordycepin/Soya- } \\
\text { cerebroside }\end{array}$ & Cordyceps militaris & miR-21 (Yang et al., 2017) & PTEN, Akt (Yang et al., 2017) & $\begin{array}{l}\text { Renal cell carcinoma (Yang et al., } \\
\text { 2017) }\end{array}$ \\
\hline & & & miR-432 (Liu S. C. et al., 2017) & $\begin{array}{l}\text { MCP-1 } \\
\text { AMPK and AKT signaling } \\
\text { pathways (Liu S. C. et al., 2017) }\end{array}$ & $\begin{array}{l}\text { Osteoarthritis } \\
\text { (Liu S. C. et al., 2017) }\end{array}$ \\
\hline 6 & Tubeimoside I & $\begin{array}{l}\text { Bolbostemma paniculatum } \\
\text { (Maxim) Franquet }\end{array}$ & miR-126-5p (Shi et al., 2017) & $\begin{array}{l}\text { VEGF-AVEGFR-2/ERK signaling } \\
\text { pathway (Shi et al., 2017) }\end{array}$ & $\begin{array}{l}\text { Non-small cell lung cancer (Shi } \\
\text { et al., 2017) }\end{array}$ \\
\hline 7 & Oridonin & $\begin{array}{l}\text { Rabdosia rubescens } \\
\text { (Hemsl.) Hara }\end{array}$ & 105 miRNAs (Gui et al., 2015) & / & $\begin{array}{l}\text { Laryngeal cancer (Gui et al., } \\
\text { 2015) }\end{array}$ \\
\hline
\end{tabular}


TABLE 1 | Continued

\begin{tabular}{|c|c|c|c|c|c|}
\hline No. & $\begin{array}{l}\text { Name of } \\
\text { ingredient }\end{array}$ & Original plant & ncRNA target & Gene/protein/pathway & Disease \\
\hline \multirow[t]{9}{*}{8} & Curcumin & Curcuma longa L. & miR-208 (Guo H. et al., 2015) & CDKN1A (Guo H. et al., 2015) & $\begin{array}{l}\text { Prostate cancer (Guo H. et al., } \\
\text { 2015; Cao et al., 2017; Liu W. L. } \\
\text { et al., 2017; Zhang et al., 2018b) }\end{array}$ \\
\hline & & & $\begin{array}{l}\text { miR-145 } \\
\text { IncRNA-ROR (Liu W. L. et al., } \\
2017 \text { ) }\end{array}$ & $\begin{array}{l}\text { CCND1, CDK4, OCT4, CD44, } \\
\text { and CD133 (Liu W. L. et al., } \\
\text { 2017) }\end{array}$ & \\
\hline & & & miR-143 (Cao et al., 2017) & PGK1, FOXD3 (Cao et al., 2017) & \\
\hline & & & miR-98 (Liu W. L. et al., 2017) & $\begin{array}{l}\text { LIN28A, MMP 2, MMP9 (Liu W. } \\
\text { L. et al., 2017) }\end{array}$ & $\begin{array}{l}\text { Lung cancer (Tang et al., 2010; } \\
\text { Liu W. L. et al., 2017) }\end{array}$ \\
\hline & & & miR-186* (Tang et al., 2010) & / & \\
\hline & & & miR-7 (Ma et al., 2014) & SET8 (Ma et al., 2014) & $\begin{array}{l}\text { Pancreatic cancer (Ma et al., } \\
\text { 2014) }\end{array}$ \\
\hline & & & miR-30c (Lu et al., 2017) & MTA1 (Lu et al., 2017) & $\begin{array}{l}\text { Paclitaxel-resistant } \\
\text { non-small-cell lung cancer (Lu } \\
\text { et al., 2017) }\end{array}$ \\
\hline & & & $\begin{array}{l}\text { miR-29b-1-5p (Zhou S. et al., } \\
\text { 2017) }\end{array}$ & $\begin{array}{l}\text { PPARG, RRM2, SRSF1, EPAS1, } \\
\text { MAPK, mTOR, PI3K-AKT, } \\
\text { AMPK, TNF } \\
\text { RAS signaling pathways (Zhou S. } \\
\text { et al., 2017) }\end{array}$ & $\begin{array}{l}\text { Adriamycin-resistant breast } \\
\text { cancer (Zhou S. et al., 2017) }\end{array}$ \\
\hline & & & $\begin{array}{l}\text { IncRNA AK294004 (Wang Q. } \\
\text { et al., 2014) }\end{array}$ & Cyclin D1(Wang Q. et al., 2014) & $\begin{array}{l}\text { Radioresistant nasopharyngeal } \\
\text { carcinoma (Wang N. et al., 2014) }\end{array}$ \\
\hline
\end{tabular}

miR-29b-1-5p

miR-29b-3p

miR-6068

miR-6790-5p

miR-4417 (Zhou et al., 2018)

miR-122

miR-221 (Zhang S. et al., 2017)

IncRNA AK125910 (Guo Y. et al., 2015)

miR-155 (Ma F. et al., 2017)

miR-17-5p (Tian L. et al., 2017)

9 Shikonin

Lithospermum erythrorhizon Sieb. et Zucc.

miR-106b (Huang and Hu, 2018)

miR-128 (Wei et al., 2016)

miR-143 (Liu et al., 2015)
DDIT4, EPAS1, VEGFA, RPS14, and DCDC2 (Zhou et al., 2018)

FGF2, MMP2, VEGF, HGF, TF, FVII (Zhang S. et al., 2017)

TNF- $\alpha$, IL-6 PI3K/AKT pathway (Ma F. et al., 2017)

WNT signaling pathway effector TCF7I2 (Tian L. et al., 2017) miR-106b/PTEN/AKT/mTOR signaling pathway (Huang and $\mathrm{Hu}, 2018)$

BAX (Wei et al., 2016)

BAG3 (Liu et al., 2015)

MMP-9 (Li W. et al., 2015)
Hepatocellular Carcinoma (Guo Y. et al., 2015; Liu W. L. et al., 2017)

LPS-induced inflammatory response (Ma F. et al., 2017)

Adipogenic differentiation (Tian L. et al., 2017)

Endometrioid endometrial cancer (Huang and Hu, 2018)

Breast cancer (Wei et al., 2016) Glioblastoma (Liu et al., 2015) Glioma (Li W. et al., 2015) 
TABLE 1 | Continued

\begin{tabular}{|c|c|c|c|c|c|}
\hline No. & $\begin{array}{l}\text { Name of } \\
\text { ingredient }\end{array}$ & Original plant & ncRNA target & Gene/protein/pathway & Disease \\
\hline 11 & Honokiol & Magnolia grandiflora & miR-34a (Avtanski et al., 2015) & $\begin{array}{l}\text { STAT3 } \\
\text { WNT1-MTA1- } \beta \text {-catenin signaling } \\
\text { (Avtanski et al., 2015) }\end{array}$ & $\begin{array}{l}\text { Breast tumor (Avtanski et al., } \\
\text { 2015) }\end{array}$ \\
\hline 12 & Schisandrin B & $\begin{array}{l}\text { Schisandra sphenanthera } \\
\text { Rehd. et Wils. }\end{array}$ & $\begin{array}{l}\text { miR-150 } \\
\text { IncRNA BCYRN1 (Zhang X. Y. } \\
\text { et al., 2017) }\end{array}$ & $\begin{array}{l}\text { miR-150/ IncRNA BCYRN1/ cell } \\
\text { proliferation axis (Zhang X. Y. } \\
\text { et al., 2017) }\end{array}$ & Asthma (Lu et al., 2016) \\
\hline \multirow{5}{*}{13} & & & $\begin{array}{l}\text { miR-200c (Karimi Dermani et al., } \\
\text { 2017) }\end{array}$ & $\begin{array}{l}\text { Vimentin, ZEB-1, E-cadherin } \\
\text { (Karimi Dermani et al., 2017) }\end{array}$ & \\
\hline & & & miR-155 (Ma C. et al., 2017) & $\begin{array}{l}\text { TNF- } \alpha, \text { IL-6, MAPKs, } \\
\text { STAT1/STAT3, and SOCS1 (Ma } \\
\text { C. et al., 2017) }\end{array}$ & $\begin{array}{l}\text { LPS-induced inflammatory } \\
\text { response (Ma C. et al., 2017) }\end{array}$ \\
\hline & & & $\begin{array}{l}\text { miR-663 } \\
\text { miR-155 (Tili et al., 2010) }\end{array}$ & $\begin{array}{l}\text { JUNB, JUND, activator protein-1 } \\
\text { (Tili et al., 2010) }\end{array}$ & Malignancies (Tili et al., 2010) \\
\hline & & & miR-96 (Bian et al., 2017) & BAX (Bian et al., 2017) & $\begin{array}{l}\text { Hypoxia/ischemia-induced brain } \\
\text { injury (Bian et al., 2017) }\end{array}$ \\
\hline & & & $\begin{array}{l}\text { miR-13 } \\
\text { miR-124 (Zhao et al., 2013) }\end{array}$ & CREB, BDNF (Zhao et al., 2013) & $\begin{array}{l}\text { Alzheimer's disease (Zhao et al., } \\
\text { 2013) }\end{array}$ \\
\hline 14 & $\begin{array}{l}\text { Soybean } \\
\text { Isoflavones }\end{array}$ & Glycine max (Linn.) Merr. & $\begin{array}{l}\text { miR-29a } \\
\text { miR-1256 (Li et al., 2012) }\end{array}$ & TRIM68, PGK-1 (Li et al., 2012) & Prostate cancer (Li et al., 2012) \\
\hline \multirow{5}{*}{17} & & & $\begin{array}{l}\text { miR-146b } \\
\text { miR-155 (Xuan et al., 2017) }\end{array}$ & $\begin{array}{l}\text { CRP, ox-LDL, IL-1 } 1 \beta, \text { IL-6, IL-12, } \\
\text { TNF- } \alpha \text {, CCL-2, CD } 40 \text {, and } \\
\text { MMP-2 (Xuan et al., 2017) }\end{array}$ & $\begin{array}{l}\text { Atherosclerosis (Xuan et al., } \\
\text { 2017) }\end{array}$ \\
\hline & & & miR-133 (Zhang et al., 2012) & $\begin{array}{l}\text { MAPK ERK1/2 (Zhang et al., } \\
\text { 2012) }\end{array}$ & Hypoxia (Zhang et al., 2012) \\
\hline & & & $\begin{array}{l}\text { miR-1 (Shan et al., 2009; Zhang } \\
\text { et al., 2010) }\end{array}$ & SRF, Kir2.1 (Shan et al., 2009) & $\begin{array}{l}\text { Arrhythmias post-AMI (Shan } \\
\text { et al., 2009) }\end{array}$ \\
\hline & & & & $\begin{array}{l}\text { Cx43, SRF, MEF2, } \\
\text { P38 MAPK signal pathway } \\
\text { (Zhang et al., 2010) }\end{array}$ & $\begin{array}{l}\text { Myocardial infarction (Zhang } \\
\text { et al., 2010) }\end{array}$ \\
\hline & & & miR-107 (Yang et al., 2015) & $\begin{array}{l}\text { GLT-1, glutamate (Yang et al., } \\
\text { 2015) }\end{array}$ & $\begin{array}{l}\text { Cerebral I/R injury (Yang et al., } \\
\text { 2015) }\end{array}$ \\
\hline \multirow[t]{2}{*}{18} & Baicalin & $\begin{array}{l}\text { Scutellaria baicalensis } \\
\text { Georgi }\end{array}$ & miR-191a (Wang L. et al., 2017) & ZO-1 (Wang L. et al., 2017) & $\begin{array}{l}\text { Inflammatory bowel disease } \\
\text { (Wang L. et al., 2017) }\end{array}$ \\
\hline & & & miR-294 (Wang J. et al., 2017) & $\begin{array}{l}\text { c-jun and c-fos (Wang J. et al., } \\
\text { 2017) }\end{array}$ & $\begin{array}{l}\text { Inhibition of proliferation (Wang J. } \\
\text { et al., 2015) }\end{array}$ \\
\hline
\end{tabular}


TABLE 1 | Continued

\begin{tabular}{|c|c|c|c|c|c|}
\hline No. & $\begin{array}{l}\text { Name of } \\
\text { ingredient }\end{array}$ & Original plant & ncRNA target & Gene/protein/pathway & Disease \\
\hline \multirow[t]{2}{*}{19} & Cinnamaldehyde & Cinnamomum cassia Presl. & $\begin{array}{l}\text { miR-21 } \\
\text { miR-155 (Qu et al., 2018) }\end{array}$ & $\begin{array}{l}\text { TNF- } \alpha, \text { IL-1 } 1 \beta, \text { IL-6, AKT, mTOR, } \\
\text { COX2 (Qu et al., 2018) }\end{array}$ & Ulcerative colitis (Qu et al., 2018) \\
\hline & & & $\begin{array}{l}\text { has-circ-0043256, miR-1252 } \\
\text { (Tian F. et al., 2017) }\end{array}$ & $\begin{array}{l}\text { has-circ-0043256/miR- } \\
\text { 1252/ITCH axis } \\
\text { WNT/ } \beta \text {-catenin pathway (Tian F. } \\
\text { et al., 2017) }\end{array}$ & $\begin{array}{l}\text { Non-small cell lung cancer (Tian } \\
\text { F. et al., 2017) }\end{array}$ \\
\hline 21 & $\begin{array}{l}\text { Carvacrol/ } \\
\text { Thymol }\end{array}$ & $\begin{array}{l}\text { Origanum vulgare } \mathrm{L} \text {. or wild } \\
\text { bergamot }\end{array}$ & $\begin{array}{l}\text { miR-155 } \\
\text { miR-146a } \\
\text { miR-21 (Khosravi and Erle, 2016) }\end{array}$ & $\begin{array}{l}\text { TLR2, TLR4, SOCS1, SHIP1 } \\
\text { (Khosravi and Erle, 2016) }\end{array}$ & Asthma (Khosravi and Erle, 2016) \\
\hline 22 & $\begin{array}{l}\text { 3-acetyl-11- } \\
\text { keto- } \beta \text {-boswellic } \\
\text { acid }\end{array}$ & Boswellia serrata & miR-155 (Sayed et al., 2018) & $\begin{array}{l}\text { P-|kB- } \alpha \text {, carbonyl protein, } \\
\text { SOCS-1 (Sayed et al., 2018) }\end{array}$ & $\begin{array}{l}\text { Neuroinflammation (Sayed et al., } \\
\text { 2018) }\end{array}$ \\
\hline 24 & Polydatin & $\begin{array}{l}\text { Polygonum cuspidatum } \\
\text { Sieb. et Zucc. }\end{array}$ & miR-214 (Zhou et al., 2016) & $\begin{array}{l}\text { Blood glucose, ALT, AST, TC, } \\
\text { TG, LDL-C, HDL-C, MDA, SOD } \\
\text { (Zhou et al., 2016) }\end{array}$ & $\begin{array}{l}\text { Atherosclerosis with liver } \\
\text { dysfunction (Zhou et al., 2016) }\end{array}$ \\
\hline \multirow[t]{2}{*}{25} & Ampelopsin & Ampelopsis grossedentata & miR-21 (Yang D. et al., 2018) & $\begin{array}{l}\text { eNOS, DDAH1, NO, and ADMA } \\
\text { (Yang D. et al., 2018) }\end{array}$ & $\begin{array}{l}\text { Endothelial dysfunction (Yang D. } \\
\text { et al., 2018) }\end{array}$ \\
\hline & & & miR-34a (Kou et al., 2016) & $\begin{array}{l}\text { SIRT1-mTOR signal pathways } \\
\text { (Kou et al., 2016) }\end{array}$ & $\begin{array}{l}\text { Neurodegenerative diseases } \\
\text { (Kou et al., 2016) }\end{array}$ \\
\hline \multirow[t]{2}{*}{26} & Icariine & $\begin{array}{l}\text { Epimedium brevicornu } \\
\text { Maxim. }\end{array}$ & miR-34c (Liu et al., 2016) & $\begin{array}{l}\text { RUNX2, JNKs, and p38, } \\
\text { NF-kB pathways (Liu et al., 2016) }\end{array}$ & $\begin{array}{l}\text { Bacteria-induced bone loss } \\
\text { diseases (Liu et al., 2016) }\end{array}$ \\
\hline & & & miR-21 (Li J. et al., 2015) & $\begin{array}{l}\text { PTEN, RECK, Caspase-3, and } \\
\text { BCL-2 (Li J. et al., 2015) }\end{array}$ & Ovarian cancer (Li J. et al., 2015) \\
\hline 29 & Phlorizin & $\begin{array}{l}\text { Acanthopanax senticosus } \\
\text { (Rupr. et Maxim.) Harms }\end{array}$ & miR-135b (Choi et al., 2016) & $\begin{array}{l}\text { p63, PCNA, integrin } \alpha 6 \text {, integrin } \\
\beta 1 \text {, and type IV collagen (Choi } \\
\text { et al., 2016) }\end{array}$ & Skin aging (Choi et al., 2016) \\
\hline 30 & Osthole & Cnidium monnieri (L.) Cuss. & miR-107 (Xiao et al., 2017) & $\begin{array}{l}\text { A } \beta \text {, BACE1, and LDH (Xiao et al., } \\
\text { 2017) }\end{array}$ & $\begin{array}{l}\text { Alzheimer's disease (Xiao et al., } \\
\text { 2017) }\end{array}$ \\
\hline \multirow[t]{5}{*}{31} & $\begin{array}{l}\text { Panax } \\
\text { Notoginseng } \\
\text { Saponins }\end{array}$ & $\begin{array}{l}\text { Panax notoginseng (Burk.) } \\
\text { F. H. Chen. }\end{array}$ & miR-29c (Liu L. et al., 2017) & $\begin{array}{l}\text { Collagen (Col) 1a1, Col1a2, } \\
\text { Col3a1, Col5a1, FBN1, TGFß1 } \\
\text { (Liu L. et al., 2017) }\end{array}$ & $\begin{array}{l}\text { Myocardial injury and fibrosis (Liu } \\
\text { L. et al., 2017) }\end{array}$ \\
\hline & & & $\begin{array}{l}\text { miR-146b-5p (Wang J. et al., } \\
\text { 2017) }\end{array}$ & / & $\begin{array}{l}\text { Oxidative damage (Wang J. } \\
\text { et al., 2017) }\end{array}$ \\
\hline & & & miR-34a (Lai et al., 2018) & $\begin{array}{l}\text { miR-34a/SIRT1/p53 pathway } \\
\text { (Lai et al., 2018) }\end{array}$ & Senescence (Lai et al., 2018) \\
\hline & & & miR-18a (Yang Q. et al., 2014) & CD34, VWF (Yang Q. et al., 2014) & $\begin{array}{l}\text { Tumor complicated with } \\
\text { myocardial ischemia (Yang Q. } \\
\text { et al., 2014) }\end{array}$ \\
\hline & & & miR-222 (Yang Q. et al., 2016) & $\begin{array}{l}\text { p27 and PTEN } \\
\text { Met/miR-222 axis (Yang Q. et al., } \\
\text { 2016) }\end{array}$ & $\begin{array}{l}\text { Lewis lung carcinoma (Yang Q. } \\
\text { et al., 2016) }\end{array}$ \\
\hline 32 & Tetrandrine & $\begin{array}{l}\text { Stephania tetrandra S. } \\
\text { Moore. }\end{array}$ & $\begin{array}{l}\text { miR-27b } \\
\text { miR-125b (Ning et al., 2016) }\end{array}$ & $\begin{array}{l}\text { VEGFC, BCL2L12, COL4A3, } \\
\text { FGFR2 (Ning et al., 2016) }\end{array}$ & $\begin{array}{l}\text { Hypertrophic scar (Ning et al., } \\
\text { 2016) }\end{array}$ \\
\hline
\end{tabular}


TABLE 1 | Continued

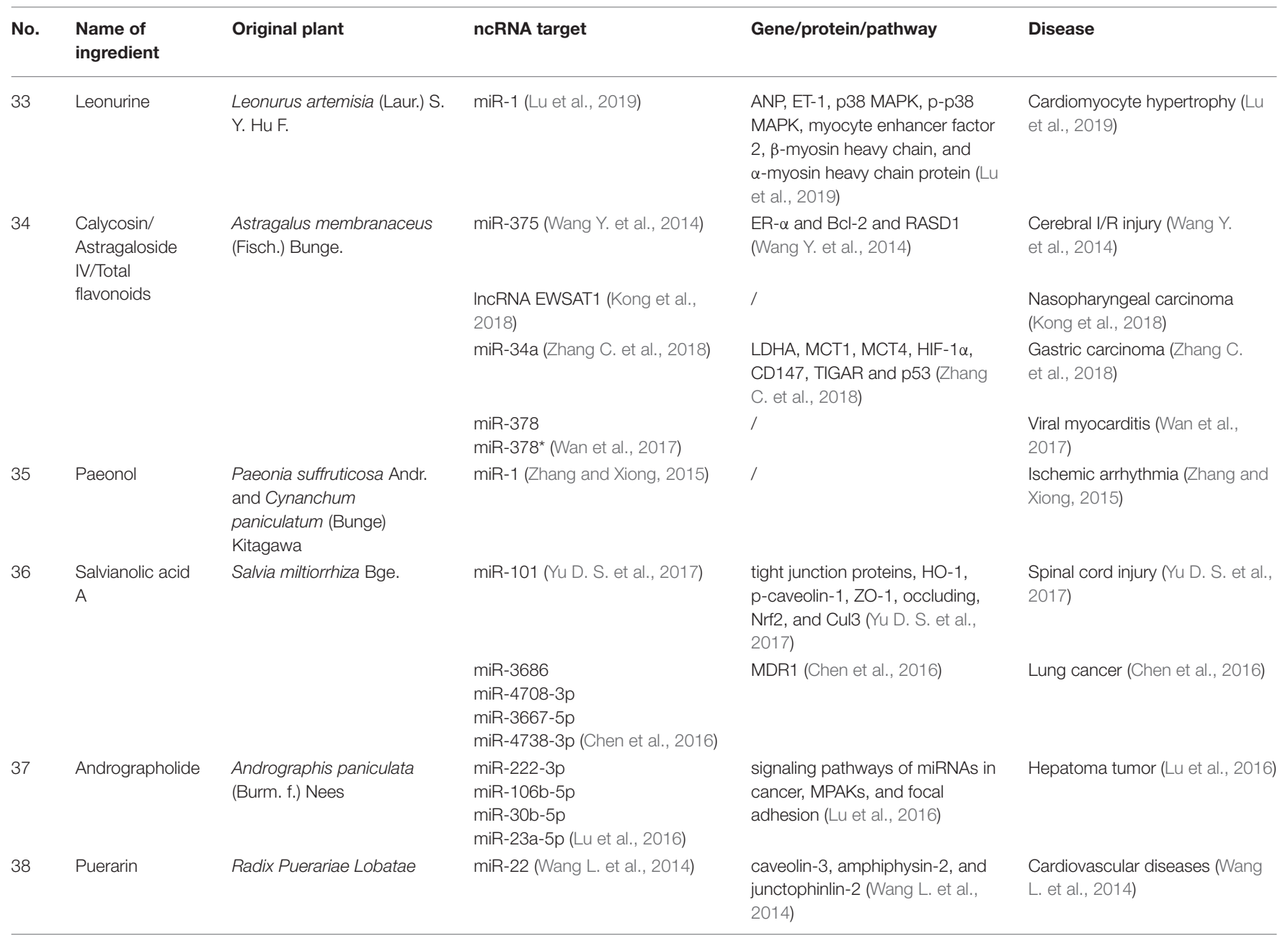

urinary systems, such as diarrhea, ulcer, jaundice, and urinary infection, as well as dermatological diseases, including eczema. Newly reported researches (Luo et al., 2014; Chai et al., 2018) have found the anti-cancer activity of two extracts from Coptis chinensis Franch. one of which is BBR. It's indicated that BBR affects apoptotic pathways in various cancers through regulation of multiple miRNAs. For example, BBR exerts significantly protective effects in multiple myeloma (MM) through targeting several miRNAs. BBR down-regulates the expression of miR99a 125b, miR-17 92, miR-106 25 (Feng et al., 2015), and miR-21 (Luo et al., 2014), thereby influencing the P53, ERB, and MAPK signaling pathways, leading to acceleration of apoptosis and growth inhibition. Moreover, BBR suppresses MM cell viability through down-regulating miR-19a/92a expression (Yin et al., 2018). Further, BBR can up regulate miR-23a in hepatocellular carcinoma (HCC) (Wang N. et al., 2014), as well as miR-152, miR-429, and miR-29a in colorectal cancer (Huang et al., 2017) in a P53-dependent manner. By inducing NEK6 inhibition and transcriptional activation of the P53-associated tumor suppressor genes, P21 and GADD45 $\alpha$, BBR induces cell death, G2/M cell cycle arrest, and tumor growth suppression in
HCC cells; in contrast, miR-23a inhibition can attenuate these BBR-mediated functions (Wang N. et al., 2014). Besides, BBR also regulates cell cycle and inhibits cell proliferation in melanoma A375 cells through promoting miR-34a, miR-154, miR-26a, and miR-124 expression, as well as suppressing target genes CDK4, CyclinD1, CyclinE, and CDK2 (Yang L. H. et al., 2016).

Additionally, BBR can enhance cellular sensitivity to chemotherapeutic drugs, helping to address the problem of drug resistance. In ovarian and gastric cancers, BBR can enhance cisplatin sensitivity by regulating the expression of miR-93 (Chen et al., 2015) and miR-203 (You et al., 2016), respectively, thus inducing apoptosis. Furthermore, there is evidence that BBR can function together with other compound. It has a synergistic antiproliferative effect on colorectal cancer when combined with NVP-AUY922. The potential mechanism underlying this phenomenon was reported to be suppression of CDK4 and induction of miR-296-5p-mediated inhibition of Pin1- $\beta$-catenin-cyclin D1 signaling, resulting in cell growth arrest (Su et al., 2015).

Interestingly, BBR also has protective effects against obesity, steatotic liver and insulin resistance. It inhibits cell viability, cell 
differentiation, and triglyceride content in a dose- and timedependent manner, through marked induction of miR-27a and miR-27b; while miR-27a and miR-27b inhibitors can counteract this repressive function of $\mathrm{BBR}(\mathrm{Wu}$ et al., 2016). Steatotic liver results from disordered lipid metabolism, where lncRNA MRAK052686, NRF2 (Yuan et al., 2015), and miR-373 (Li C. H. et al., 2018) are down-regulated. BBR can reverse the abnormal expression of these genes in steatotic liver, thereby inhibiting the AKT-mTOR-S6K signaling pathway and preventing the development of hepatic steatosis (Li C. H. et al., 2018). In addition, through downregulating miR-29a-3p in insulin resistant HepG2 cells, BBR can increase the mRNA and protein expression of IRS1, leading to regulation of the insulin receptor signaling pathway protein (Mao et al., 2018).

Based on the above results, it is clear that BBR possesses different pharmacological effects via targeting miRNAs. Particularly, it shows obvious advantages for treatment of MM and digestive cancers, mainly through its activities in promotion of apoptosis and inhibition of cell growth. More importantly, its direct anticancer properties are strongly associated with P53 signaling. Therefore, BBR presents as promise for potential future use in cancer treatment.

\section{Artesunate}

Artesunate (ART, dihydroartemisinin-12-alpha-succinate; Chem. 2) is a sesquiterpene lactone extracted from the leafy portions of the Chinese herb, Artemisia annua L. It's the semisynthetic derivative of artemisinin which is widely known to be a natural antimalarial medicine ( $\mathrm{Tu}, 2016)$. Recently, the function of ART in cancer therapy, by targeting lncRNA and promoting cell apoptosis, was newly identified. The lncRNA, UCA1, is up-regulated in prostate cancer tissues and positively correlated with poor prognosis (Zhou Y. et al., 2017). ART significantly decreased the expression of lncRNA UCA1, thereby regulating the downstream miR-184/BCL-2 axis, inducing apoptosis, and inhibiting metastatic ability. Furthermore, these protective effects could be reversed by overexpression of lncRNA UCA1, indicating that it is a target of ART (Zhou Y. et al., 2017). Hence, ART exhibits anticancer properties through regulating the ceRNA crosstalk of the lncRNA UCA1/miR-184/BCL-2 axis in prostate cancer. Nevertheless, additional evidence to support these findings is lacking and the stability of this regulatory network requires validation.

\section{Triptolide/Triptonide}

Triptolide (TP, (3bs,4as,5as,6r,6ar,7as,7bs,8as,8bs)-6hydroxy-6a-isopropyl-8b-methyl-3b,4,4a,6,6a,7a,7b,8b,9,10decahydrotrisoxireno[6,7:8a,9:4b,5]phenanthro[1,2-c]furan1(3h)-one; Chem. 3) and Triptonide (TN, $3 \mathrm{bS}, 4 \mathrm{aS}, 5 \mathrm{aS}, 6 \mathrm{aS}$, 7aS,7bS,8aS,8bS)-6a-isopropyl-8b-methyl-3b,4,4a,7a,7b,8b, 9,10-octahydrotrisoxireno[6,7:8a,9:4b,5]phenanthro[1,2-c] furan-1,6(3H,6aH)-dione; Chem. 4) are both diterpene lactone components originated from Tripterygium wilfordii Hook. f. (TwHf) that has traditionally been used for treatment of rheumatoid arthritis (RA). A recent study has revealed that TwHf exerts its anti-rheumatic effects through regulation of miR-146a, which is over-expressed in patients with RA and negatively correlated with prognosis. TwHf treatment could significantly decrease miR-146a expression. Moreover, miR-146a could be used as a predictor of patient clinical response to TwHf (Chen Z. Z. et al., 2017).

Researches about TP and TN broaden the traditional application and generate new pharmacological effect for cancer treatment. TP has been found to exert anticancer activities in lung cancer. It can induce apoptosis and suppress proliferation through inhibiting miR-21 and increasing expression of phosphatase and tensin homolog (PTEN) protein in non-small cell lung cancer. Moreover, miR-21 upregulation could reverse the effect of TP on cell viability and PTEN (Li et al., 2016). Furthermore, TP treatment is also reported to regulate 227 miRNAs and markedly decrease the migration, invasion, and metastasis of lung cancer cells (Reno et al., 2015). In addition, TP can promote apoptosis and suppress cell proliferation in hepatocellular carcinoma, potentially via inhibition of miR-17-92 and miR-106b-25, in a c-MYC-dependent manner, leading to an increase of BIM, PTEN, and P21 levels (Li S. G. et al., 2018).

However, TN shows significant therapeutic advantages in human nasopharyngeal carcinoma (NPC). It promotes NPC apoptosis and cell cycle arrest, as well as inhibition of cell migration and invasion, without toxicity to nasopharyngeal epithelial cells. This anti-cancer activity is attributed to suppression of IncRNA THOR, followed by downregulation of IGF2BP1 mRNA targets involving Myc, IGF2, and Gli1. Furthermore, lncRNA THOR knockout enhances the protection of TN on NPC; while IncRNA THOR overexpression reverses $\mathrm{TN}$-induced treatment in cells. In vivo, TN administration also obviously impedes subcutaneous NPC xenograft growth in mice. Similarly, lncRNA THOR knockout inhibits xenograft growth (Wang et al., 2019).

Therefore, TP and TN are attractive candidate chemotherapeutic agents against the above cancers. With regard to TP, PTEN is an important target; while TN possesses anti-cancer activity in vitro and in vivo through regulating lncRNA THOR/IGF2BP1 signaling. Nevertheless, as the extracts from TwHf with general toxicity (Chen et al., 2008; Luo et al., 2018), the effectiveness and safety of $\mathrm{TP}$ and $\mathrm{TN}$ require additional confirmation.

\section{Ailanthone}

Ailanthone (AIL, Picrasa-3,13(21)-diene-2,16-dione, 11,20epoxy-1,11,12-trihydroxy-, (1-beta,11-beta,12-alpha)-; Chem. 5) is a water-soluble quassinoid extracted from the root bark of Ailanthus altissima (Mill.) Swingle. Traditionally, the root bark was used for improvement of itching, bleeding and diarrhea in TCM theory. However, AIL has been newly found to possess anti-tumor activity in different tumors (Chen Y. et al., 2017; Peng et al., 2017; Yang P. et al., 2018). Among those, inhibitory effect of human vestibular schwannomas (VSs) induced by AIL is correlated with miRNA. A research has demonstrated that AIL cleaves caspase 3 and caspase 9, promotes Beclin-1, LC3-II accumulation, and decreases p62, cyclin D1 expression, thus increasing apoptotic cell rate. The upstream mechanism may be suppression of miR-21, and the Ras/Raf/MEK/ERK and mTOR pathways, leading to apoptosis and autophagy in AIL-treated 
cells. In addition, miR-21 overexpression can attenuate the regulation of AIL on Ras/Raf/MEK/ERK and mTOR pathways, as well as apoptosis and autophagy, indicating miR-21 can be the treatment target of AIL in VSs (Yang P. et al., 2018).

\section{Cordycepin}

Cordycepin (COR, 9-(beta-D-3'-Deoxyribofuranosyl)adenine; Chem. 6) is the main bioactive ingredient of Cordyceps militaris, a precious CHM. The medicinal herb has immunitystrengthening effect, and has been already used as a health care product in clinical practice. Modern researches broaden the application of COR in various cancers (Wang et al., 2016; Liang et al., 2017; Yu X. et al., 2017). Specifically, treatment of COR for renal cell carcinoma (RCC) is attributed to regulation of miR-21 and PTEN phosphatase. It's indicated that COR down-regulates miR-21 expression and Akt phosphorylation, yet promotes PTEN phosphatase in RCC Caki-1 cells, resulting in induction of apoptotic cell death and suppression of cell migration. Furthermore, miR-21 mimic or PTEN siRNA can markedly abolish the above effects induced by COR (Yang et al., 2017). Therefore, it's confirmed that COR possesses proapoptosis and anti-migration function through regulating miR21/PTEN axis.

In addition, soya-cerebroside (Chem 7), another extracts from Cordyceps militaris is demonstrated to be anti-inflammatory for osteoarthritis (OA). It suppresses AMPK and AKT signaling pathways, and then promotes miR-432 expression in OA synovial fibroblasts, leading to inhibition of monocyte chemoattractant protein-1 (MCP-1), monocyte migration and infiltration, as well as cartilage degradation (Liu S. C. et al., 2017). As a result, soya-cerebroside exerts protective effect for OA partially via regulating miR-432, MCP-1, AMPK and AKT pathways; while in this study a clear functional relationships among those factors are not reported.

\section{Tubeimoside I}

Tubeimoside I (TBMSI, nosyl]- $\beta$-D-glucopyranosyl]oxy]-2,23 -dihydroxy-,28-(O- $\beta$-D-xylopyranosyl-( $1 \rightarrow 3)$-O-6-deoxy$\alpha$-L-mannopyranosyl-( $1 \rightarrow 2)-\alpha$-L-arabinopyranosyl)ester, intramol. ester, $[2 \beta, 3 \beta(S), 4 \alpha]$ - Tubeimoside TUBEIMOSIDE $\mathrm{A}(\mathrm{P})$; Chem. 8) is the main triterpenoid saponin originated from Bolbostemma paniculatum (Maxim) Franquet. which has detoxification and detumescent activities. Recent studies have revealed the pharmacological action of TBMS1 as a potential anti-cancer agent (Wang et al., 2011; Gu et al., 2016). A research demonstrated that TBMS1 can promote apoptosis, and attenuate migration, invasion of non-small cell lung cancer cells. The underlying mechanism is attributed to upregulation of miR-126-5p, followed by inactivation of VEGF-A/VEGFR2/ERK signaling pathway. MiR-126-5p inhibitor can reverse the downregulated VEGF-A and VEGFR-2 induced by TBMS1 treatment; moreover, both miR-126-5p inhibitor, and VEGF-A, VEGFR-2 overexpression upregulate the mRNA expression and phosphorylation of MEK1 and ERK. Significantly, apoptosis, migration and invasion of TBMS1-treated cells can be reversed by either miR-126-5p inhibitor or ERK activator (Shi et al.,
2017). From the above results, it can be concluded that miR-1265p/VEGF-A/VEGFR-2/ERK signaling is the protective pathway of TBMS1 for cancer therapy.

\section{Oridonin}

Oridonin (ORI, (14R)-7-alpha,20-Epoxy-1-alpha,6-beta,7,14tetrahydroxykaur-16-en-15-one, Chem. 9) is a ent-kaurane diterpenoid compound mainly originated from Rabdosia rubescens (Hemsl.) Hara. Traditionally, the herb was convinced to have the effect of detoxification, circulation promotion and pain relief in China. Currently, ORI is illustrated to participate in the treatment of several tumors via different regulatory pathways. It's reported that human laryngeal cancer cell is accelerated to apoptosis after ORI treatment through inhibiting EGFR signaling. Similarly, EGFR suppression increased ORI-induced apoptosis by the promotion of oxidative stress, and activation of intrinsic and extrinsic apoptotic pathways (Kang et al., 2010). Moreover, 105 miRNAs are involved in the regulation of ORI-treated pancreatic cancer (Gui et al., 2015). Therefore, it's possible that miRNAs involve in the anti-cancer activity of ORI; however, whether EGFR is the downstream target of miRNAs deserves more researches.

\section{ANTI-PROLIFERATION AND ANTI-MIGRATION EFFECTS OF CHMS}

Abnormal cell proliferation is involved in the pathogenesis of many diseases. In particular, the proliferation and invasion of cancer cells are primary contributors to poor patient outcomes (Gao et al., 2017). In addition, asthma is also associated with the cell proliferation and migration in airway smooth muscle (Zhao et al., 2016). Hence, suppression of cell proliferation and migration are critical methods for treatment of these diseases. Excitingly, some bioactive ingredients of $\mathrm{CHMs}$ have been found to inhibit the proliferation and migration of both cancer and asthma cells through targeting miRNA, lncRNA, or ceRNA crosstalk.

\section{Curcumin}

Curcumin (CUR, (1E,6E)-1,7-Bis(4-hydroxy-3methoxyphenyl)hepta-1,6-diene-3,5-dione; Chem. 10) is a phenolic compound extracted from Curcuma longa L., which was traditionally used as painkiller in rheumatism and other bone and joint diseases. Recent studies have found that CUR can also act as an anticancer agent, via miRNA and lncRNA targets. CUR inhibits miR-208 and activates expression of the cell cycle suppressor, CDKN1A, resulting in dose-dependent suppression of prostate cancer cell proliferation (Guo H. et al., 2015). Further, CUR can significantly increase miR-143 and decrease PGK1 expression, while ectopic expression of FOXD3 can enhance the regulatory effect of CUR on miR-143, thereby inhibiting the proliferation and migration of prostate cancer cells (Cao et al., 2017). Further studies reveal that CUR also acts on human prostate cancer stem cells (HuPCaSC). CUR treatment increases the expression of miR-145 and decreases levels of IncRNA-ROR, the cell cycle proteins CCND1, CDK4, and the stem cell markers OCT4, CD44, and CD133. The tumorigenicity 
of these cells is thereby significantly reduced through inhibition of their proliferation, invasion, and cell cycle arrest (Liu T. et al., 2017). Moreover, expression levels of miR-770-5p and miR-1247 in the DLK1-DIO3 imprinted gene cluster were significantly up-regulated, leading to suppression of HuPCaSC proliferation and invasion in vitro (Zhang et al., 2018a). CUR also promotes the expression of miR-98 in lung cancer, thus inhibiting cell growth and migration (Liu W. L. et al., 2017). By reducing miR$186^{*}$ expression, it induces apoptosis and decreases cell viability in lung cancer cells as well (Tang et al., 2010). Furthermore, CUR inhibits both proliferation and accelerates apoptosis in bladder, gastric, non-small cell lung, pancreatic cancers, and hepatic carcinoma via the up-regulation of miR-203 (Saini et al., 2011), miR-33b (Sun et al., 2016), miR-192-5p (Jin et al., 2015), miR-7 (Ma et al., 2014), and lncRNA AK125910 (Guo Y. et al., 2015), respectively.

CUR has also been reported to increase the sensitivity of nonsmall-cell lung cancer (Lu et al., 2017), breast cancer (Zhou S. et al., 2017), and nasopharyngeal carcinoma (Wang Q. et al., 2014) to chemotherapy drugs by targeting ncRNAs including miR-30c, miR-29b-1-5p, and lncRNA AK294004, respectively, along with their downstream genes. Moreover, CUR can exert synergistic effects in combination with other compounds, to suppress cell proliferation and invasion and induce apoptosis in glioblastoma ( $\mathrm{Wu}$ et al., 2015), breast cancer (Guo et al., 2013), and hepatocellular carcinoma (Zhang S. et al., 2017). In glioblastoma, miR-378 was found to promote the anticancer effect of CUR by regulating p38 expression, demonstrating the mutual interaction of miRNA and CUR (Li et al., 2017). Furthermore, CUR is reported to exert anti-inflammatory effects (Ma F. et al., 2017) and to inhibit adipogenic differentiation (Tian L. et al., 2017).

Notably, as liposome technology is a good method for targeting drug delivery system that can solve the solubility problems of poorly soluble drugs (Allen and Cullis, 2004). A research has used this technology to produce CUR-loaded liposome, increasing solubility and oral bioavailability of CUR, as well as reducing first pass effect of hepar. This drug combination can also promote sensitivity of breast cancer cells to chemotherapy, through regulating different miRNAs of miR29b-1-5p, miR-29b-3p, miR-6068, miR-6790-5p, and miR-4417, as well as their target genes involving DDIT4, EPAS1, VEGFA, RPS14, and DCDC2 (Zhou et al., 2018).

These data demonstrate that CUR can suppress cell proliferation, growth, and metastasis in various cancers by targeting ncRNAs. In particular, CUR has obvious advantages for the treatment of prostate cancer through its regulation of cancer and cancer stem cells. Moreover, the synergistic effects of CUR with other chemotherapies provide new alternative strategies to address drug resistance. Excitingly, structural improvement of CUR not only ensures its anti-cancer effect, but also promotes the bioavailability.

\section{Shikonin}

Shikonin (SHK, 5,8-dihydroxy-2-((1R)-1-hydroxy-4-methyl3-penten-1-yl)-1,4-naphthalen-edione; Chem. 11) is a naphthoquinone derivative compound. SHK is extracted from the root of the natural herbal medicine, Lithospermum erythrorhizon Sieb. et Zucc. This plant was generally used to treat rash, pox, measles, and urticaria in TCM. Modern studies have discovered broader applications for this compound in cancer, by revealing its anti-proliferation function, which is reported to be associated with targeting of miRNAs. SHK can inhibit proliferation and promote apoptosis by modulating the miR106b/PTEN/AKT/mTOR signaling pathway in endometrioid endometrial cancer (Huang and $\mathrm{Hu}, 2018$ ). Moreover, SHK inhibits the proliferation of breast cancer cells through downregulation of tumor-derived exosomal miR-128 (Wei et al., 2016). In addition, the anticancer activity of SHK in glioblastoma is enhanced by miR-143 by reducing the expression of the anti-apoptosis regulator, BAG3, which is a functional target of miR-143 (Liu et al., 2015).

Overall, the regulatory relationships between SHK and miRNAs are mutual. SHK could target miR-106b and miR-128 in endometrioid endometrial cancer and breast cancer to prevent cell proliferation. Further, miR-143 expression influences the anticancer activity of SHK in glioblastoma. Finally, the results reviewed above demonstrate that the anti-proliferation activity of $\mathrm{SHK}$ in cancers can be attributed to its interactions with miRNAs.

\section{Paeoniflorin}

Paeoniflorin [PF, 5b-((Benzoyloxy)methyl)tetrahydro-5hydroxy-2-methyl-2,5-methano-lH-3,4-dioxacyclobuta(cd) pentalen-1a(2H)-yl-beta-D-glucopyranoside; Chem. 12] is the main active ingredient of Paeonia lactiflora Pall., which was commonly used to regulate blood circulation and relieve pain in TCM theory. Recent investigations have revealed roles for PF in vasodilation (Goto et al., 1996), anti-inflammation (Chen et al., 2013; Hu et al., 2018), microcirculation improvement (Zhou et al., 2011), anti-oxidation (Chen et al., 2011), and anti-cancer (Wang et al., 2012) activities. Specifically, PF exhibits protective activity in glioma via suppression of cell proliferation and promotion of apoptosis. The potential underlying mechanism may involve upregulation of miR-16 and downregulation of matrix metalloproteinase-9 (MMP-9), which are differentially expressed in glioma tissues and cells compared with healthy controls (Li W. et al., 2015). This result lays the foundation for treatment of cancer using PF; however, supporting evidence is insufficient and more investigations are needed.

\section{Honokiol}

Honokiol (HNK, 5,3'-Diallyl-2,4'-dihydroxybiphenyl; Chem. 13) is a bioactive polyphenol isolated from Magnolia grandiflora. Although the flower was traditionally valued as ornamental, it contains the phenolic ingredient, HNK, which has been shown to have antimicrobial activity (Clark et al., 1981). A recent study discovered that HNK has anti-tumor activity; it can markedly inhibit the growth, invasion, and migration of breast cancer cells, and breast-tumor-xenograft growth induced by leptin. HNK promotes the expression of miR-34a, and inhibits WNT1-MTA1- $\beta$-catenin signaling, through suppression of STAT3 phosphorylation and recruitment of STAT3 to the promoter of miR-34a (Avtanski et al., 2015). Hence, HNK has demonstrated a protective effect on breast cancer in a 
diet-induced-obese mouse model with high leptin levels and could serve as a new endocrine therapy drug for patients with obesity-related breast cancer accompanied by negative estrogen and progesterone receptors; however, the research described above was limited to animal experiments, and further evidence in humans is required, thus clinical trials are warranted to further investigate HNK.

\section{Schisandrin B}

Schisandrin B (Sch B, 7-dimethyl-ethoxy-stereoisomer;benzo $(3,4) \operatorname{cycloocta}(1,2-f)(1,3)$ benzodioxole, 5,6,7,8-tetrahydro-1,2,

3,13-tetram; Chem. 14) is a type of lignan, extracted from Schisandra sphenanthera Rehd. et Wils. The original fruit was commonly used to relieve symptoms of cough, gasp, abnormal sweating, nocturnal emission, thirst, and palpitations, under TCM theory. Although it was widely used to treat various diseases in ancient China, its specific target and underlying mechanism of action were unclear. A recent study of Sch B provided information about the involvement of ncRNA. Sch $B$ may increase the expression of miR-150 and subsequently reduce levels of the lncRNA BCYRN1 in airway smooth muscle cells (ASMCs) of asthmatic rats. By regulating these two ncRNAs, Sch B suppresses the proliferation, viability, and migration of ASMCs; therefore, the study generated evidence that partially explains the mechanism underlying the activity of Sch B against asthma (Zhang X. Y. et al., 2017). Moreover, Sch B can mediate ceRNA crosstalk between miR-150 and lncRNA BCYRN1, further establishing an miR-150/lncRNA $\mathrm{BCYRN1/cell} \mathrm{proliferation} \mathrm{axis;} \mathrm{however,} \mathrm{as} \mathrm{a} \mathrm{new} \mathrm{regulatory}$ mechanism influencing asthma, the stability of the ceRNA crosstalk requires further investigation.

\section{Resveratrol}

Resveratrol (RES, 3,4',5-trihydroxystilbene; Chem. 15) is a natural phenol stilbenoid that is mainly found in food, including the skin of grapes and blueberries, and several CHMs, including Morus alba L., Polygonum cuspidatum Sieb. et Zucc., and Rubus idaeus L. It is considered to protect individuals from cardiovascular diseases, as well as dietary and metabolic diseases (Bradamante et al., 2004; Baur et al., 2006; Lagouge et al., 2006). Recently, its anticancer properties have also been evaluated by researchers and RES has been used as a dietary supplement (Garvin et al., 2006; Kalra et al., 2008; Roy et al., 2009). RES can down-regulate the lncRNA, MALAT1, and up-regulate miR$200 c$, as well as inhibiting WNT/ $\beta$-catenin signaling, leading to suppression of cell invasion, metastasis, and migration in colorectal cancer (Ji et al., 2013; Karimi Dermani et al., 2017). Moreover, by significantly decreasing oncogenic miR-221 and regulating $\mathrm{NF}-\kappa \mathrm{B}$ and TFG, RES exerts inhibitory effects on melanoma cells, both in vitro and in vivo (Wu and Cui, 2017). In glioma, RES inhibits cell proliferation, arrests the cell cycle in $S$ phase, and induces apoptosis in vitro, through down-regulation of miR-21, miR-30a-5p, and miR-19, as well as regulating their targets, including P53, PTEN, EGFR, STAT3, COX-2, NF-кB, and the PI3K/AKT/mTOR pathway (Wang G. et al., 2015).

RES also has anti-inflammatory effects. It can reduce expression of miR-155 and promote that of its target gene, suppressor of cytokine signaling 1 (SOCS1), leading to subsequent inhibition of the inflammatory factors, TNF- $\alpha$, IL6, MAPKs, and STAT1/STAT3 (Ma C. et al., 2017). Interestingly, by increasing miR-663 expression, RES down-regulates miR-155, thus acting as both an anti-inflammatory and an anticancer agent (Tili et al., 2010). Furthermore, RES exhibits neuroprotective effects. It promotes miR-96 and inhibits its target gene, BAX, resulting in prevention of oxygen/glucose deprivation/reoxygenation-induced apoptosis and brain damage, while this protective function can be reversed by miR-96 inhibitor (Bian et al., 2017). In Alzheimer's disease, RES also improves long-term memory formation and induction of long-term potentiation of hippocampus CA1 neurons, through down-regulation of miR134 and miR-124, and up-regulation of CREB and BDNF (Zhao et al., 2013). Therefore, RES is a potential therapeutic agent against cancers, cerebral ischemia, Alzheimer's disease, and other inflammatory conditions.

\section{Soybean Isoflavones}

Soybean isoflavones (SIF, 3-phenyl-4h-1-benzopyran-4-one; Chem. 16) are extracted from Glycine max (Linn.) Merr. They act as phytoestrogens in mammals and have been used as dietary supplements. SIF are associated with breast cancer (Douglas et al., 2013; Takagi et al., 2015). Recently, they have also been demonstrated to suppress cell growth and invasion in prostate cancer. A potential mechanism underlying the anti-prostate cancer activity of SIF is its promotion of miR-29a and miR-1256, leading to down-regulation of TRIM68 and PGK-1 by inhibiting methylation of the miR-29a and miR-1256 promoters (Li et al., 2012). Nevertheless, as a controversial ingredient with weak estrogen-like properties, the influence of SIF on hormonereceptor-positive cancers has caused widespread concern. Therefore, research is needed to determine the effectiveness and safety of SIF in the context of different cancers.

\section{Matrine}

Matrine (MAT, (7aS,13aR,13bR,13cS)-Dodecahydro$1 \mathrm{H}, 5 \mathrm{H}, 10 \mathrm{H}$-dipyrido[2,1-f:3',2', $1^{\prime}$-ij] (Memczak et al., 2013; Song et al., 2017)naphthyridin-10-one; Chem. 17) is the main alkaloid extract from Sophora flavescens Ait which was commonly used for diseases of dysentery, eczema and jaundice in China. Modern pharmacological research shows that MAT has protective activity in melanoma, as evidenced by inhibition of proliferation and invasion, and promotion of apoptosis in melanoma cell lines. By downregulating miR-19b-3p expression, MAT increases the protein and mRNA expression of PTEN, a direct target of miR-19b-3p. Similarly, miR-19b-3p downregulation can imitate the effect of MAT; while PTEN silencing reverses the protection induced by MAT (Wei et al., 2018). As a result, MAT can exert anti-cancer activity in melanoma via regulating miR-19b-3p/PTEN axis.

\section{Corylin}

Corylin (CL, 3-(2,2-dimethylchromen-6-yl)-7-hydroxychromen4-one; Chem. 18) is the flavonoid compound extracted from Psoralea corylifolia Linn. In TCM practice, Psoralea corylifolia Linn. was often used for degenerative bone and joint diseases. 
Newly reported studies have revealed its application in inflammation (Kim et al., 2016; Hung et al., 2017) and cancer (Chen et al., 2018). The anti-cancer activity induced by CL is related to upregulation of tumor suppressor lncRNA GAS5 and its downstream anticancer pathways activation. As a result, the proliferation, migration, and invasiveness, as well as epithelialmesenchymal transition are all inhibited in hepatocellular carcinoma cells. Moreover, lncRNA GAS5 silencing can attenuate the above inhibitory effect of CL. In an animal experiment, $\mathrm{CL}$ is observed to obviously retard tumor growth as well, with no significant physiological toxicity (Chen et al., 2018). Taken together, lncRNA GAS5 may act as the treatment target of CL in hepatocellular carcinoma; however, specific downstream gene of lncRNA GAS5 still needs further study.

\section{ANTI-INFLAMMATORY EFFECTS OF CHMS}

Inflammation is a common pathological process involved in many diseases, including coronary heart disease, inflammatory bowel disease, myocarditis, asthma, and neuroinflammatory disorder (Harrington, 2017; Robinson et al., 2017; Mahajan et al., 2018); however, both non-steroidal anti-inflammatory drugs and immunosuppressive agents have clear side effects (Shah and Gecys, 2006; Ahmad et al., 2010). Consequently, safe and effective anti-inflammatory drugs for the treatment of the basic pathologies underlying the above diseases are still needed. Several bioactive ingredients of CHMs are reported to target miRNA or ceRNA crosstalk, thereby exerting anti-inflammatory effects.

\section{Tanshinone IIA}

Tanshinone IIA (Tan IIA, Phenanthro [1, 2-b]furan-10, 11-dione, 6, 7, 8, 9-tetrahydro-1, 6, 6-trimethyl; Chem. 19) is a lipophilic diterpenoid extracted from the root of Salvia miltiorrhiza Bge. Under TCM theory, the original herb is considered to promote blood circulation. Recent studies have illustrated that Tan IIA has cardioprotective activity (Shang et al., 2012; Feng et al., 2016) and injection of sodium Tan IIA sulfonate has been widely used as an adjunctive therapy for cardiovascular diseases in China (Yu M. L. et al., 2018). A potential mechanism underlying its inhibition of inflammation (Pan et al., 2017; Cheng et al., 2018), and an upstream regulator, is miRNA. Tan IIA can reduce the expression levels of cytokines, chemokines, and acutephase proteins, including TLR4, MyD88, GM-CSF, sICAM-1, CXCl-1, and MIP-1 $\alpha$. Moreover, it significantly inhibits the mRNA expression levels of IL- $1 \beta$, TNF- $\alpha$, and COX-2, thereby suppressing lipopolysaccharides (LPS) -induced activation of the TLR4-NF- $\mathrm{B}$ pathway. Furthermore, expression of miR-155, miR-147, miR-184, miR-29b, and miR-34c is also reduced by Tan IIA, and these may be upstream regulators in anti-inflammation processes (Fan et al., 2016). In addition, by down-regulation of miR-146b and miR-155, Tan IIA significantly reduces the levels of inflammatory factors, including CRP, ox-LDL, IL-1 $\beta$, IL-6, IL-12, TNF- $\alpha$, CCL-2, CD40, and MMP-2, thereby exerting protective functions in atherosclerosis induced by Porphyromonas gingivalis (Xuan et al., 2017).

Another study indicated that Tan IIA can also inhibit apoptosis caused by hypoxia. Through increasing miR-133 expression and activating the stress-induced protein kinase, MAPK ERK1/2, Tan IIA enhances resistance to hypoxic exposure in neonatal cardiomyocytes (Zhang et al., 2012). Treatment with Tan IIA has also been illustrated to reverse the abnormal expression of miR-1, SRF, and MEF2, and participates in suppression of the p38 MAPK signaling pathway, restoring declined $\mathrm{I}(\mathrm{K} 1)$ current density and Kir2.1 and $\mathrm{Cx} 43$ protein levels, thus lowering the incidence of arrhythmogenesis and mortality after myocardial infarction, and improving cardiac function (Shan et al., 2009; Zhang et al., 2010). These results provide a partial explanation for the anti-inflammatory and anti-hypoxia activity of Tan IIA via miRNAs in cardiovascular diseases; in particular, miR-155 may be a specific target of Tan IIA in inflammation.

Additionally, an aqueous extract from Salvia miltiorrhiza Bge., named magnesium lithospermate B (MLB, magnesium (2R)-3-(3,4-dihydroxyphenyl)-2-[(E)-3-[(2S,3S)-2-(3,4dihydroxyphenyl)-3-[(2R)-3-(3,4-dihydroxyphenyl)-1-oxido1-oxopropan-2-yl] oxycarbonyl-7-hydroxy-2,3-dihydro-1benzofuran-4-yl]prop-2-enoyl]oxypropanoate; Chem. 20), has neuroprotective effect in ischemia/reperfusion (I/R) injury. I/R injury can lead to miR-107 upregulation, glutamate transporter 1 (GLT-1) suppression and glutamate accumulation, increasing neurological deficit score, infarct volume and cellular apoptosis (Yang Z. B. et al., 2014). MLB treatment improves I/R-induced cerebral injury through reversing the abnormal expressions of miR-107, GLT-1 and glutamate (Yang et al., 2015).

The above results may help to throw light on the underlying mechanisms of Tan IIA and MLB for the treatment of cardiovascular and cerebrovascular diseases from the perspective of miRNA; however, it should be noted that the pharmacological action of Salvia miltiorrhiza Bge. is not limited to ncRNAs (Zhu et al., 2017).

\section{Baicalin}

Baicalin (BA, 7-D-glucuronic acid-5,6-dihydroxy-flavone; Chem. 21) is a flavone glycoside extracted from Scutellaria baicalensis Georgi, which was commonly applied for the treatment of respiratory and digestive diseases in CHM. The traditional treatment effects may be related to regulation of inflammatory responses. TNF- $\alpha$ stimulation promotes the expression of miR-191a, causing downregulation of ZO-1 mRNA and protein. BA pretreatment could reverse the effects of ZO-1 and miR-191a expression induced by TNF- $\alpha$, leading to improved viability and migration of rat small intestine epithelial cells. Furthermore, knockdown of miR-191a expression significantly increased BAL-induced ZO-1 protein expression, thereby enhancing the protective effect of BA on cell motility (Wang L. et al., 2017). These data suggest that miR-191a may be an upstream target of $\mathrm{BA}$ in the treatment of inflammatory bowel disease; moreover, the therapeutic effects of BA can also be influenced by miR-191a.

Also, another research illustrates the proliferative inhibition of mouse embryonic stem cells induced by baicalin. Baicalin suppresses the expression of miR-294, c-jun and c-fos; while miR-294 overexpression could significantly reverse the above 
effect of baicalin, indicating miR-294 may be the treatment target (Wang J. et al., 2015).

Therefore, BA exerts anti-inflammatory and anti-proliferative effects by targeting miRNAs and emerges as a potential treatment agent for digestive disease. Further, as BA remains one of the most frequently used medicines for the treatment of cough and phlegm, the activity of BA in respiratory disease warrants similar studies.

\section{Cinnamaldehyde}

Cinnamaldehyde (CA, 3-phenylprop-2-enaldehyde; Chem. 22) is a conjugated aromatic aldehyde extracted from the bark of the Chinese herb, Cinnamomum cassia Presl. According to TCM theory, the traditional plant can enhance the function of "yang qi" (a substance with excitatory function in TCM) and is often used to relieve symptoms of weakness. Recent studies have broadened the application of this preparation to the treatment of cerebrovascular diseases, ulcerative colitis, and cancer (Zhao et al., 2015; Tian F. et al., 2017; Qu et al., 2018), where it acts by exerting anti-inflammatory or ncRNA regulatory functions. CA improves symptoms of weight loss, disease activity index, and infiltration of inflammatory cells, by decreasing the levels of pro-inflammatory cytokines, including TNF- $\alpha$, IL- $1 \beta$, and IL-6, as well as the NLRP3 inflammasome, miR-21, and miR155 , in both colon tissue and macrophages. Moreover, levels of reactive oxygen species were also reduced, along with the phosphorylation of AKT, mTOR, and COX2 proteins. Further experiments revealed similar suppression of IL-1 $\beta$ and IL-6 in response to miR-21 or miR-155 inhibitors, demonstrating that these inflammatory factors are positively regulated by miR-21 or miR-155 (Qu et al., 2018). As a result, CA suppresses the miR$21 / \mathrm{miR}-155 / \mathrm{IL}-1 \beta / \mathrm{IL}-6$ axis to exert its protective function in ulcerative colitis.

CA also has anti-cancer activity through regulation of ceRNA crosstalk and can suppress cell proliferation and induce apoptosis in non-small cell lung cancer. Through upregulation of hascirc-0043256 and ITCH expression, CA inhibits the WNT/ $\beta$ catenin pathway, while this function can be partially abolished by miR-1252, indicating that miR-1252 may participate in has-circ-0043256-related regulation. Moreover, has-circ-0043256 knockdown can reverse the effects of CA on cells (Tian F. et al., 2017). Consequently, has-circ-0043256/miR-1252/ITCH crosstalk may contribute to the anticancer activity of CA.

\section{Geniposide}

Geniposide (GEN, methyl (1S,4aS,7aS)-7-(hydroxymethyl)-1[(2S,3R,4S,5S,6R)-3,4,5-trihydroxy-6-(hydroxymethyl)oxan-2yl]oxy-1,4a,5,7a-tetrahydrocyclopenta[c]pyran-4-carboxylate; Chem. 23) is derived from Gardenia jasminoides Ellis, a traditional antipyretic and detoxifying CHM. A recent research reported GEN has effects of anti-inflammatory and cardiomyocyte protection in LPS-injured H9c2 cells. It up-regulates miR-145 expression, inhibits pro-inflammatory factors of IL-6, TNF- $\alpha$, and MCP-1, and then suppresses the MEK/ERK pathway, thus promoting cell viability and inhibiting apoptosis. Moreover, miR-145 inhibitor could reverse the above protective function induced by GEN pretreatment ( $\mathrm{Su}$ et al., 2018). Therefore, GEN becomes a potential therapeutic agent for myocarditis in practice by targeting miR-145 and anti-inflammation in cardiomyocyte.

\section{Carvacrol/Thymol}

Carvacrol (Car, 5-Isopropyl-2-methylphenol; Chem 24) and Thymol (Thy, 2-Isopropyl-5-methylphenol; Chem. 25) are isolated from the essential oil of Origanum vulgare L. or wild bergamot. They are isomers and belong to monoterpenoid phenol. Traditionally, Origanum vulgare L. was applied for the treatment of cold and heatstroke. Bergamot can relieve pain and vomit under TCM theory. A research further expanded the applicable scope of these herbs by studying the two bioactive ingredients. Car/Thy can suppress the allergic inflammation in asthma by regulating miRNAs and inflammatory factors. In chitin-induced model, expression levels of miR-155, miR146a and miR-21, promotor of pro-inflammatory cytokines, are upregulated. Furthermore, SOCS1 and SHIP1, targets of miR155 and negative regulators of TLR-mediated inflammation, are demonstrated to be inhibited by chitin. However, Car/Thy treatment can reverse the abnormal expressions of TLR2, TLR4, SOCS1, SHIP1, and miR-155, miR-146a, miR-21 (Khosravi and Erle, 2016). These results preliminarily establish the relationships between anti-inflammation effect of Car/Thy and miRNAs; but the specific target and corresponding regulatory network are not reported regrettably.

\section{Boswellic Acids}

Boswellic acids are extracted from oleo-gum-resin of Boswellia serrata, a traditional CHM with promoting blood circulation and pain relief function. Boswellic acids contain different ingredients, among which 3-acetyl-11-keto- $\beta$ boswellic acid (AKBA, (3R,4R,6aR,6bS,8aR,11R,12S,14bS)3-acetyloxy-4,6a,6b,8a,11,12,14b-heptamethyl-14-oxo$1,2,3,4 \mathrm{a}, 5,6,7,8,9,10,11,12,12 \mathrm{a}, 14 \mathrm{a}-$ tetradecahydropicene4-carboxylic acid; Chem. 26) possesses the most potent anti-inflammatory activity (Siddiqui, 2011; Sayed et al., 2018). AKBA can attenuate the behavioral dysfunction in LPS-induced neuroinflammation, similarly with that effect of dexamethasone. Moreover, AKBA lowers expression of miR-155, P-IкB- $\alpha$, and carbonyl protein, and increases contents of normal cytokine and SOCS-1, resulting in effects of antiapoptotic and anti-amyloidogenic (Sayed et al., 2018). Therefore, regulation of miR-155 and downstream protein helps to reveal the possible mechanism underneath AKBA's positive role in neuroinflammatory disorders; however, the specific target deserves more verification.

\section{ANTI-ATHEROSCLEROSIS EFFECTS OF CHMs}

Atherosclerosis is the basic pathology underlying coronary artery disease, cerebral infarction, and other vascular diseases (Pothineni et al., 2017; Li Q. et al., 2018). Medicines with antiatherosclerosis activities are therefore highly significant for the prevention and treatment of these diseases. Statins are currently the main drugs used against atherosclerosis; however, when taken 
for long periods of time, they risk impairing liver function and causing muscle lysis, particularly in elderly patients (Guyton, 2006; Ramakumari et al., 2018). Therefore, better drugs with relatively few side effects are needed and CHMs represent a good resource in this context. Recent studies have identified three bioactive ingredients of $\mathrm{CHMs}$ as regulators of atherosclerosis through targeting miRNA or lncRNA.

\section{Sinapic Acid}

Sinapic Acid (SA, 3,5-dimethoxy-4-hydroxycinnamic acid; Chem. 27) is the bioactive ingredient isolated from seeds of the Chinese herb, Sinapis alba L. The seeds were commonly used to treat cough, phlegm, limb numbness, and chronic abscess. A recent study reported protective effects of SA in atherosclerosis, which helped to partially explain the original application of the seed to treat limb numbness. The lncRNA MALAT1 is significantly up-regulated in rats with diabetic atherosclerosis and low-dose SA treatment can suppress this abnormal expression. Subsequently, pyroptotic death of bone marrow derived macrophages is inhibited, accompanied by decreased expression of ET-1 and IL-1 $\beta$, and the pyroptotic proteins, ASC, NRLP3, and Caspase-1 (Han et al., 2018). Hence, SA exerts anti-inflammatory activity and prevents pyroptosis, thus exerting anti-atherosclerosis effects, through targeting lncRNA MALAT1; however, the efficacy and safety of SA as a potential treatment agent require verification by additional studies.

\section{Polydatin}

Polydatin (PLD, 3,4,5-trihydroxystilbene-3-beta-monoglucoside; Chem. 28), also known as Piceid, is the bioactive ingredient from Polygonum cuspidatum Sieb. et Zucc. This herb was traditionally used for the treatment of jaundice and cough. However, PLD has also been found to exert protective effects against cardiac hypertrophy (Zhang et al., 2015a), insulin resistance, and hepatic steatosis (Zhang et al., 2015b). Further, a recent study has revealed the underlying regulatory action of PLD in atherosclerosis with liver dysfunction. The findings indicated that PLD treatment can markedly lower increased blood glucose, serum ALT, AST, TC, TG, and LDL-C in mice with high-fat diet. Simultaneously, changes in HDL-C, MDA, SOD, and miR214 were also improved in liver tissue (Zhou et al., 2016). This study indicates that PLD can be therapeutically effective in complex diseases by regulating various factors. In addition, PLD shows great potential as a complement to treatment for statin-induced liver damage via its anti-atherosclerosis and liver protection properties; however, the above study only reported the expression levels of various factors induced by PLD, rather than systematically studying the relationships between miR-214 and its target genes. Therefore, further in-depth investigations are required in the future.

\section{Ampelopsin}

Ampelopsin

[(2r,3r)-3,5,7-trihydroxy-2-(3,4,5-trihydrox yphenyl)chroman-4-one; Chem. 29], also called dihydromyricetin (DHM), is the main flavonoid compound from Ampelopsis grossedentata. The original herb has effects of detoxification, anti-inflammatory and analgesic, commonly used as a dietary supplement. DHM is now demonstrated to impede atherosclerotic process by regulating endothelial dysfunction (Yang D. et al., 2018), and exert anti-aging effect against neurodegenerative diseases (Kou et al., 2016). It inhibits miR-21 expression and then improves endothelial dysfunction induced by TNF- $\alpha$, accompanied by suppression of abnormal expression of eNOS, DDAH1, NO, and ADMA, as well as improvement of tube formation and migration. Furthermore, miR-21 blockade can produce similar effects with DHM treatment; while miR-21 overexpression abolishes the above protection. Additionally, improvement of endothelial dysfunction can be reversed by a non-specific NOS inhibitor, indicating DHM ameliorates vascular endothelial function and inhibits atherosclerosis by targeting miR-21-mediated DDAH1/ADMA/NO signal pathway (Yang D. et al., 2018).

Another study reveals that miR-34a is upregulated in D-galinduced brain aging rats; while DHM management can inhibit the abnormal expression. Moreover, DHM suppresses apoptosis and ameliorates impaired autophagy of neurons in D-gal-injured hippocampus tissue, by up-regulating SIRT1 and downregulating mTOR signal pathways (Kou et al., 2016). Therefore, DHM possesses anti-aging effect partially through regulating miR-34a-mediated SIRT1-mTOR signal pathway, showing important role for the treatment of neurodegenerative diseases.

From the above results, it can be seen that DHM exerts not only anti-atherosclerosis effect, but also anti-aging function by targeting miRNAs and downstream signaling pathways.

\section{ANTI-INFECTION EFFECTS OF CHMS}

Antibiotics and antiviral drugs are basic treatments for infectious diseases; however, a deteriorating situation caused by antibiotic abuse, drug-resistance, and viral mutations is shifting the focus of research attention to other therapeutic and complementary drugs for treatment of these conditions (Miyoshi et al., 2015; Jiang et al., 2019). To date, two bioactive ingredients of CHMs have been found to contribute to the treatment of infection through regulation of miRNAs. These substances can protect the human body from pathological damage, although they do not directly induce pathogen resistance.

\section{Icariine}

Icariine [ICA, 2-(4'-methoxyphenyl)-3-rhamnosido-5hydroxyl-7-glucosido-8-(3'-methyl-2-butylenyl)-4-chromanone; Chem. 30] is the main bioactive flavonoid glucoside extracted from Epimedium brevicornu Maxim. Under TCM, this herb was considered to nourish "yang qi" and generally applied for treatment of osteoarticular and reproductive diseases. ICA can suppress osteoclast bone resorption and bone loss, indicating great potential for use as a treatment agent for both aseptic loosening and bacteria-induced bone loss (Zhang et al., 2015; Liu et al., 2016). Specifically, ICA can restore LPS-induced bone loss, without obvious cytotoxicity. This product can downregulate expression of the osteogenic inhibitor, miR-34c, while it up-regulates levels of the key transcription factor, RUNX2, thereby inducing osteogenic differentiation and mineral nodule formation. Moreover, miR-34c overexpression can reverse these 
effects of ICA. Additionally, ICA markedly suppresses LPSinduced activation of JNK, p38, and NF-kB pathways, leading to therapeutic effects in diseases causing bacteria-induced bone loss, such as osteomyelitis and septic arthritis (Liu et al., 2016). Interestingly, ICA also exhibits anticancer activity in ovarian cancer via down-regulation of miR-21 expression. This subsequently induces PTEN, RECK, and Caspase-3 activity, while BCL-2 protein expression is inhibited, leading to suppression of cell proliferation and increased apoptosis (Li J. et al., 2015). Based on these findings, miR-34c appears to facilitate the mechanisms underlying the role of ICA in infectious bone loss. Furthermore, the identification of miR-21 suggests a potential new application of ICA in cancer therapy. Therefore, there is promise that additional currently unknown functions of this medicinal herb could be determined by studying ncRNA and related regulatory networks.

\section{Ginsenosides}

Ginsenosides (GS, (3S,5R,8R,9R,10R,14R,17S)-17-(2-hydroxy -6-methylhept-5-en-2-yl)-4,4,8,10,14-pentamethyl-2,3,5,6,7,9, $11,12,13,15,16,17$-dodecahydro- $1 \mathrm{H}$-cyclopenta[a]phenanthren3-ol; Chem. 31), also referred to as panaxosides, are a class of natural steroid glycosides and triterpene saponins. These products include various active components, such as ginsenoside $\mathrm{Re}, \mathrm{Rg}, \mathrm{Rh}, \mathrm{Rb}$, and Rc. GS are mainly isolated from Panax ginseng C. A. Mey., a valuable herb with nourishing effects and a long history of use in ancient China. At present, GS products are not only used to promote health, but also for their activity as immune regulators in many diseases (Jiang Z. et al., 2017; Shin et al., 2018; Yu X. et al., 2018). GS exert a cytoprotective effect, thereby promoting cell viability on avian influenza H9N2/G1 infection. During this process, the expression of miR-15b was up-regulated, while production of IP-10 was markedly inhibited. Furthermore, cytometry and TUNEL analyses indicated that ginsenoside Re prevents apoptosis and DNA damage in human endothelial cells caused by H9N2/G1 (Chan et al., 2011). These results are inconsistent with the traditional concept that GS is only suitable for treatment of sub-optimal health status or chronic diseases and greatly expand the potential for application of GS for treatment of acute infectious diseases in the future.

\section{ANTI-SENESCENCE EFFECTS OF CHMs}

Cell senescence is the irreversible state in which cells undergo cycle arrest responding to various factors (Watanabe et al., 2017). It participates in biological processes involving embryonic development, wound healing and aging, closely relating to organismal aging and diseases, and thus arousing widespread concerns in researchers (Watanabe et al., 2017; de Magalhães and Passos, 2018). Currently, several bioactive ingredients of CHMs have been found to act positive roles in anti-senescence.

\section{Salidroside}

Salidroside [SAL, 2-(4-Hydroxyphenyl)ethyl beta-Dglucopyranoside; Chem. 32] is the main bioactive extract from Rhodiola rosea L. with effects of nourishing "yang qi" and promoting blood circulation under TCM theory. Modern pharmacological study further revealed that the medicinal herb not only exerts anti-fatigue ability, but also improves resistance to hypoxia (Li et al., 2014). Moreover, SAL has been supported to possess anti-senescence activity. The potential mechanism is related to regulation of multiple miRNAs expression. Through upregulating let-7c, let-7e, miR-3620, and decreasing expression of miR-411, miR-24-2-5p and miR-485-3p in the aging cells, SAL participates in several pathways involving $\mathrm{p} 53$, transcription factor CREB and AKT/mTOR signaling (Zhang J. et al., 2017). As is known that both let-7 and mTOR are aging-related (Marasa et al., 2010; Wu et al., 2013), and the former factor can directly inhibit the expression of the latter (Marcais et al., 2014). Therefore, it's possible that SAL possesses anti-senescence effect by regulating let-7 and mTOR; however, the predicted regulatory relationship requires more validation in the future.

\section{Phlorizin}

Phlorizin (PZ, Phloretin-2'-O-beta-glucoside; Chem. 33) is the main active ingredient of Acanthopanax senticosus (Rupr. et Maxim.) Harms which is a traditional CHM with functions.of nourishing and enhancing strength. PZ is convinced to exert effects of anti-fatigue, learning improvement and immuneenhancing (Huang et al., 2011). Researches further reported that PZ can act as a promising agent for skin aging (Zhai et al., 2015; Choi et al., 2016). By promoting epidermal cell proliferation and self-renewal, $\mathrm{PZ}$ thickens epidermis to maintain skin structure and resistance to aging. Moreover, $\mathrm{PZ}$ increases expression of p63 and proliferating cell nuclear antigen (PCNA), as well as integrin $\alpha 6$, integrin $\beta 1$ and type IV collagen. Particularly, the mRNA of type IV collagen is also increased and possibly regulated by downregulation of miR-135b (Choi et al., 2016). As a result, miR-135b/type IV collagen axis may be the underlying regulatory mechanism of anti-senescence induced by PZ.

\section{Osthole}

Osthole (Ost, 7-methoxy-8-(3-methyl-2-butenyl)-2H-1benzopyran-2-one; Chem. 34) is mainly extracted from Cnidium monnieri (L.) Cuss. which was commonly used for nourishing "yang qi" and relieving itching in TCM practice. Current pharmacological researches newly revealed that Ost can improve memory, delay senescence and resist cell damage in Alzheimer's disease (AD) ( $\mathrm{Hu}$ et al., 2013; Zheng et al., 2013). As it's clear that beta-amyloid peptide $(A \beta)$ is the critical pathology of $\mathrm{AD}$, inhibition of $\mathrm{A} \beta$ deposition thereby becomes an important treatment strategy for the disease (Wilcock et al., 2009). Ost was reported to enhance cyclic AMP response element-binding protein (CREB) phosphorylation and then inhibit $A \beta$ cytotoxicity on neural cells (Hu et al., 2013). Further mechanism study indicates that it upregulates miR-107, and then promotes cells viability of neuron, resulting in suppression of the protein expression of $\mathrm{A} \beta$ and BACE1, as well as LDH (Xiao et al., 2017). Therefore, Ost exertes obvious neuroprotective effect through targeting miR-107 and impeding $A \beta$ deposition, presenting as a potential treatment agent for neurogenic aging and neurodegenerative disease. 


\section{INHIBITORY EFFECTS OF CHMs ON STRUCTURAL REMODELING}

Structural remodeling is an important factor that can impede the normal functions of tissues and organs. It is also the main pathological change during the late stages of various diseases, making poor prognosis and difficult treatment (Bijkerk et al., 2019; Bittencourt et al., 2019; Zhuang et al., 2019). Encouragingly, three CHM ingredients have been demonstrated to exert protective effects on this pathological change through regulation of miRNAs.

\section{Panax Notoginseng Saponins}

Panax notoginseng saponins (PNS, notoginsenoside-fe, 98\%; Chem. 35) are a chemical mixture extracted from the root of Panax notoginseng (Burk.) F. H. Chen. According to TCM theory, the traditional herb can simultaneously promote blood circulation and prevent bleeding; therefore, it was commonly used to treat coronary artery disease, stroke, gastrointestinal bleeding, irregular menstruation, and bruises. Currently, several PNS preparations, including xuesaitong injections and xuesetong capsules, are widely used to treat cardiovascular diseases (Song et al., 2017). The improvement in cardiac prognosis caused by PNS has been attributed to its regulation of miRNAs and suppression of structural remodeling. PNS was reported to increase expression of the anti-fibrotic factor, miR-29c, which is clearly reduced in mice with isoproterenol-induced myocardial fibrogenesis, leading to downregulation of its target genes: collagen (Col) 1al, Col1a2, Col3a1, Col5a1, Fbn1, and TGF $\beta 1$, thus exerting protective effects against myocardial injury and fibrosis (Liu L. et al., 2017). In addition, PNS has obvious resistance to $\mathrm{H}_{2} \mathrm{O}_{2}$-induced oxidative damage, showing anti-apoptosis activity in vascular endothelial cells (VECs) by suppressing miR-146b-5p expression (Wang J. et al., 2017). Moreover, notoginsenoside R1, one main component of PNS, can delay the process of senescence in VECs by regulating miR-34a/SIRT1/p53 pathway (Lai et al., 2018). As a result, through repairing VECs damages, PNS inhibits vascular pathological process.

PNS also has an active role in tumors complicated by myocardial ischemia where paradoxical treatment strategy existed. PNS and its major components, Rg1, Rb1, and R1, are implicated in tissue-specific regulation of angiogenesis, and can inhibit tumor growth, as well as attenuating myocardial ischemia. The potential underlying mechanism may be the downregulation of miR-18a and vascular markers (CD34 and vWF) in tumor, with simultaneous up-regulation of these factors in heart (Yang Q. et al., 2014). Notably, by modulating Met/miR222 axis, and then increasing target genes of tumor suppressor p27 and PTEN expression, PNS selectively inhibits the survival of lewis lung carcinoma cells and attenuates tumor growth in mice (Yang Q. et al., 2016).

Based on the above results, PNS appears to exert its cardioprotective function by preventing fibrosis, improving vascular endothelium, and promoting angiogenesis in the heart.
Simultaneously, considering the cardioprotection and antitumor effects through targeting miRNAs, PNS is especially suitable for patients with heart disease and tumor.

\section{Tetrandrine}

Tetrandrine (TET, 6,6',7,12-tetramethoxy-2,2'-dimethyl-1 beta-berbaman; Chem. 36) is a bisbenzylisoquinoline alkaloid extracted from Stephania tetrandra S. Moore. The medicinal plant was often used for treatment of rheumatism and edema under the theories of TCM. Notably, the source plant should not be confused with Radix Aristolochiae Fangchi which causes nephrotoxicity, despite their similar Chinese names. A recent study identified a new pharmacological effect of TET in treatment of anti-hypertrophic scarring. The underlying mechanism was suggested to be repression of DNA and collagen synthesis in scar-derived fibroblasts (Liu et al., 2001). Furthermore, by upregulating miR-27b and downregulating miR-125b, TET influenced the expression of putative targets, including VEGFC, BCL2L12, COL4A3, and FGFR2, predicted to contribute to several scar and wound healing-related signaling pathways (Ning et al., 2016). Consequently, TET has therapeutic potential for the inhibition of skin tissue hyperplasia after wounding or surgery.

\section{Leonurine}

Leonurine (LEO, 4-Guanidino-n-butyl syringate; Chem. 37) is the alkaloid compound from Leonurus artemisia (Laur.) S. Y. Hu F, which was commonly used for gynecological diseases in TCM. Newly reported results have indicated the cardioprotective effect by studying LEO activity, namely anti-atherosclerosis (Jiang $\mathrm{T}$. et al., 2017), anti-oxidation (Gao et al., 2016) and resistant to cardiomyocyte hypertrophy (Lu et al., 2019). LEO treatment can significantly reduce the surface area of hypertrophic cardiomyocytes, decrease the content of atrial natriuretic peptide (ANP), endothelin-1 (ET-1), p38 mitogen-activated protein kinase (p38 MAPK), phosphorylated p38 MAPK (p-p38 MAPK), myocyte enhancer factor 2 and $\beta$-myosin heavy chain. Moreover, it also up-regulates the expression levels of $\alpha$-myosin heavy chain protein and miR-1. Thus, by upregulating miR-1 expression and then inhibiting the activation of p38MAPK signaling pathway, LEO may inhibit AngII-induced cardiomyocyte hypertrophy and structural remodeling (Lu et al., 2019).

\section{OTHER EFFECTS OF CHMS}

Bioactive ingredients of CHMs can exert various protective effects through targeting different miRNA, IncRNA, or circRNA. Besides the above mentioned mechanisms, some ingredients also play positive roles in anti-I/R injury, anti-arrhythmia, recovery of blood-spinal cord barrier, and promotion of cardiac differentiation by targeting lncRNA and miRNA.

\section{Calycosin/Astragaloside IV}

Calycosin (CAL, 7,3'-dihydroxy-4'-methoxyisoflavone; Chem. 38) is a natural phytoestrogen derived from Astragalus membranaceus (Fisch.) Bunge. which can nourish "yang qi" and was commonly used for cardiovascular and cerebrovascular diseases in TCM practice. It's indicated that the neuroprotection 
effect of CAL is related to miRNA. CAL markedly improves the infarcted volume, brain water content, and neurological deficit in cerebral I/R injury rats, by upregulating miR-375, ER- $\alpha$ and Bcl-2, and inhibiting RASD1 expression (Wang Y. et al., 2014). Regrettably, a systematic mechanism of miR-375 and those downstream targets has not been revealed in this study.

Moreover, CAL also possesses positive role in anti-cancer, enriching the pharmacological effect and application of Astragalus membranaceus extracts (Tseng et al., 2016; Kong et al., 2018). It's demonstrated that CAL significantly impedes lncRNA EWSAT1 expression in nasopharyngeal carcinoma (NPC), followed by influenced downstream factors and pathways, leading to inhibitory growth. Furthermore, lncRNA EWSAT1 overexpression can reverse CAL-induced effect, indicating lncRNA EWSAT1 act as the specific target of CAL promisingly (Kong et al., 2018).

Additionally, Astragaloside IV (ASIV, 3-O-beta-Dxylopyranosyl-6-O-beta-D-glucopyranosylcycloastragenol;

Chem. 39), another bioactive compound of Astragalus membranaceus (Fisch.) Bunge., can ameliorate precancerous lesions of gastric carcinoma (PLGC) markedly. It lowers mRNA and protein expressions of LDHA, MCT1, MCT4, HIF-1 $\alpha$, and CD147, as well as increasing TIGAR and p53 content. Furthermore, ASIV treatment promotes miR-34a expression. As a result, ASIV improves abnormal glycolysis and dysplasia possibly via regulation of miR-34a/LDHA pathway (Zhang C. et al., 2018).

Interestingly, the total flavonoids of Astragalus membranaceus (Fisch.) Bunge. (TFA) can improve heart function damaged by viral myocarditis. By upregulating the expression of miR-378 and miR-378* in cardiomyocytes infected with coxsackie B3 virus, TFA may inhibit cardiac hypertrophy and improve prognosis (Nagalingam et al., 2013; Wan et al., 2017). Therefore, it can be speculated that the heart protection of TFA is attributed to inhibition of myocardial pathology by regulating miR-378 and miR-378*.

From the above results, it can been seen that although CAL, ASIV and TFA are extracted from the same herb, they have different targets and are applicable for distinct diseases, demonstrating the study necessity of identified ingredients and targets from CHMs.

\section{Paeonol}

Paeonol (PAE, 2' -Hydroxy-4' -methoxyacetophenone; Chem. 40) is the main bioactive ingredient of Paeonia suffruticosa Andr. and Cynanchum paniculatum (Bunge) Kitagawa. The two herbs promoted blood circulation and could be used for cardiovascular diseases in TCM practice. Further pharmacological research shows PAE significantly reduces the incidence of ischemic arrhythmia in rats, including lowered frequency of ventricular premature beat, ventricular tachycardia and ventricular fibrillation. Moreover, it markedly decreases infarct size of myocardium. The potential treatment target is miR-1 which is inhibited by PAE in cardiomyocytes (Zhang and Xiong, 2015). Nevertheless, the above study only reveals the possible regulatory relationship between PAE and miR-1, which needs more verification and further identifies the downstream target gene of miRNA.

\section{Salvianolic Acid A}

Salvianolic acid A (Sal A, (R)-3-(3,4-Dihydroxyphenyl)-2(((E)-3-(2-((E)-3,4-dihydroxystyryl)-3,4-dihydroxyphenyl)

acryloyl)oxy)propanoic acid; Chem. 41) is derived from watersoluble phenolic compound of Salvia miltiorrhiza Bge.. It has protective effects of anti-IR injury (Jiang et al., 2008; Yang et al., 2011), recovery of neurological function (Yu D. S. et al., 2017) and anti-cancer activities (Chen et al., 2016; Lu et al., 2016), the latter two pharmacological actions of which are attributed to miRNA regulation. It's reported that Sal A significantly increases expression of tight junction proteins and HO-1, and decreases p-caveolin-1 and apoptosis-related proteins, resulting in recovery of blood-spinal cord barrier integrity after spinal cord injury (SCI). Furthermore, HO-1 inhibitor can attenuate the regulation of ZO-1, occluding, and p-caveolin-1 by Sal A. The underlying target and mechanism may be upregulation of miR-101 which promotes expression of nuclear factor erythroid 2-related factor 2 (Nrf2) and HO-1. Conversely, miR-101 inhibitor accelerates the permeability of rat brain microvascular endothelial cells, and the protein of Cul3 by targeting its mRNA. As a result, Sal A improves neurological function after SCI through targeting miR-101/Cul3/Nrf2/HO-1 signaling pathway (Yu D. S. et al., 2017).

Another study indicated that Sal A can also down-regulate the expression of multidrug resistance gene MDR1 in lung cancer, thereby emerging as a new treatment agent for lung cancer resistance. The potential mechanism may be related to up-regulation of 4 miRNA expressions including miR-3686, miR4708-3p, miR-3667-5p, and miR-4738-3p (Chen et al., 2016). This study attempts to find the upstream target of Sal A against MDR1 from perspective of post-transcriptional regulation; but current result cannot directly confirm the regulatory correlation between the 4 miRNAs and MDR1. Thus, more and deeper experiments are urgently needed in the future.

\section{Andrographolide}

Andrographolide (Andro, 17-hydro-9-dehydroandrographolide; Chem. 42) is a diterpenoid lactone compound derived from Andrographis paniculata (Burm. f.) Nees, a natural anti-bacterial and anti-viral CHM. A recent study further demonstrates that Andro can inhibit hepatoma tumor growth. It promotes the expression of 22 miRNAs, but declines that of other 10 miRNAs in a xenograft mouse tumor model in vivo. Among those upregulated miRNAs, miR-222-3p, miR-106b-5p, miR-30b-5p, and miR-23a-5p are confirmed in cell experiments in vitro. Functional analysis reveals that those miRNAs are mainly involved in signaling pathways of miRNAs in cancer, MPAKs and focal adhesion. Moreover, 24 target genes involved in the above signaling pathways are illustrated to be consistent with miRNAs expression ( $\mathrm{Lu}$ et al., 2016). As a result, Andro prevents hepatoma tumor growth partially through regulating miRNA profile; whereas the specific target and underlying mechanism still need deeper study. 


\section{Puerarin}

Puerarin (PUE, 7,4'-Dihydroxy-8-C-glucosylisoflavone; Chem. 43) is the main active ingredient extracted from Radix Puerariae Lobatae which improved symptoms of fever, neck stiffness, thirst and diarrhea in ancient China. Modern researches reveal the cardiovascular protection of PUE for myocardial infarction (Zhang et al., 2006) and arrhythmia (Zhang et al., 2011). The active effects may be attributed to promotion of cardiac differentiation (Cheng et al., 2013; Wang L. et al., 2014). PUE upregulates expression of caveolin-3, amphiphysin-2 and junctophinlin-2, and then ameliorates myofibril array and sarcomeres formation, accompanied by increased t-tubules development in the embryonic stem cell-derived cardiomyocytes. Moreover, PUE suppresses the upstream regulatory factor of caveolin-3, namely miR-22, indicating miR-22/caveolin-3 axis may be the underlying mechanism of cardiomyogenesis induced by PUE (Wang L. et al., 2014).

\section{CONCLUSION}

CHM has long been a powerful weapon used by Chinese people to combat disease. Over thousands of years, practitioners of CHM have accumulated a wealth of knowledge which is used to prevent and cure diseases. The theoretical concepts of TCM act as the basis for scientific research into CHM today, including identification of the bioactive ingredients and underlying mechanisms of CHMs that could be of benefit internationally - a gift from the Chinese people to the world ( Tu, 2011, 2016). Chinese pharmacologist, Youyou Tu, and her team discovered the highly effective and low-toxicity bioactive ingredient "artemisinin" from Artemisia annua L. (also referred to as "qinghao" in Chinese), inspired by, "A Handbook of Prescriptions for Emergencies" (written around 317-420 CE), thus making an outstanding contributions to the global treatment of malaria ( $\mathrm{Tu}, 2016)$. Consequently, we became convinced that study of the bioactive ingredients of CHMs is an effective way to reveal their potential mechanisms of action and further broaden their clinical application.

By conducting the above comprehensive review, we found that bioactive ingredients of CHMs can play positive roles in treatment of cancer, cardiovascular, nervous system, respiratory, digestive, infectious, and senescence-related diseases. Through targeting various miRNAs, lncRNAs, circRNAs, or ceRNA crosstalk, these ingredients exert protective effects, including pro-apoptosis, anti-proliferation and anti-migration, anti-inflammation, anti-atherosclerosis, anti-infection, antisenescence, and anti-structural remodeling. Some miRNAs, including miR-21, miR-34a, miR-34c, miR-155, miR-29a, miR-203, miR-27b, miR-184, and miR-143, contributed to the treatment mechanisms of more than one bioactive ingredient of CHMs. In particular, miR-21 was identified as targeted and regulated by BBR (Luo et al., 2014), TP (Li et al., 2016), RES (Wang G. et al., 2015), CA (Qu et al., 2018), ICA (Li J. et al., 2015), AIL (Yang P. et al., 2018), Car/Thy (Khosravi and Erle, 2016), DHM (Yang D. et al., 2018), and COR (Yang et al., 2017), especially in its anti-cancer activities, indicating that this miRNA is stably targetable and responsive to the pharmacological effects of various CHMs. Moreover, miR-155 was associated with inflammatory responses and could be inhibited by CUR, RES, Tan IIA, CA, Car/Thy and AKBA, in inflammatoryrelated diseases (Tili et al., 2010; Fan et al., 2016; Khosravi and Erle, 2016; Ma F. et al., 2017; Xuan et al., 2017; Qu et al., 2018; Sayed et al., 2018). Thus, it is highly likely that miR-155 could represent a new treatment target for anti-inflammation. In addition, three complex ceRNA crosstalk networks were discovered to function in the therapeutic mechanisms of ART, Sch B, and CA. Specifically, ART regulates the lncRNA UCA1/miR-184/BCL-2 axis, to inhibit prostate cancer (Zhou S. et al., 2017), while the has-circ-0043256/miR-1252/ITCH axis was involved in the treatment of non-small cell lung cancer by CA (Tian F. et al., 2017). The miR-150/ lncRNA BCYRN1 axis was targeted by Sch B treatment, leading to suppression of cell proliferation in asthma (Zhang X. Y. et al., 2017). All of these complex networks provide foundations for in-depth understanding and broader application of CHMs in the near future.

The interactions between bioactive ingredients of $\mathrm{CHMs}$ with ncRNA targets are the subject of intensive and rapidly expanding research. This has helped to reveal the treatment mechanisms underlying the activities of $\mathrm{CHMs}$ and offers promising complementary and alternative treatments for diseases, based on scientific research. Although some previous reviews have revealed the increasing importance of bioactive ingredients (Huang et al., 2016; Lelli et al., 2017) or CHMs (Hong et al., 2015) in the treatment of diseases by targeting ncRNA. However, most of them mainly focused on one kind of ncRNA (particularly miRNA), or are limited to a specific disease (mostly cancer) (Mohammadi et al., 2017; Mirzaei et al., 2018); rather than overall and comprehensive ncRNA targets, ceRNA crosstalk and corresponding mechanisms. As a result, we consider it's necessary to make a systematic review about the treatment mechanisms of bioactive ingredients from CHMs by targeting miRNA, lncRNA, and circRNA. From our review, it can be seen that studies are currently in initial and exploratory phases, and several critical problems remain. First, various individual ncRNA molecules are targets of CHM bioactive ingredients; however, recent results are far from sufficient to allow understanding of the complex regulatory interactions between circRNA, IncRNA, miRNA, and mRNA in the treatment of diseases. Second, the metabolism of drugs in single cell lines and animals may differ from that in the human body; therefore, results based on basic research require further verification in clinical trials. Third, each CHM generally contains numerous ingredients and a TCM clinical prescription often consists of several CHMs; therefore, multiple targets and ceRNA crosstalk must occur and the study of classic TCM formulae will further complicate the picture.

In conclusion, ncRNAs are potential targets of CHMs and understanding of ceRNA crosstalk has helped to reveal the complex mechanisms underlying multi-target and multi-level regulation of bioactive ingredients from $\mathrm{CHMs}$. Therefore, $\mathrm{CHM}$ ingredients represent new and promising choices for future alternative disease treatments. 


\section{AUTHOR CONTRIBUTIONS}

JW and JL designed the study. YD, HC, and JG conducted searches and extracted the data. YL and YD analyzed the data. YD wrote the manuscript.

\section{REFERENCES}

Ahmad, S., Bhanji, A., Pal, S., and Karim, M. (2010). Irreversible sensorineural hearing loss: an unusual side effect of non-steroidal anti-inflammatory drugs. Int. J. Clin. Pharmacol. Ther. 48, 514-516. doi: 10.5414/CPP48514

Allen, T. M., and Cullis, P. R. (2004). Drug delivery systems: entering the mainstream. Science 303, 1818-1822. doi: 10.1126/science.1095833

Avtanski, D. B., Nagalingam, A., Kuppusamy, P., Bonner, M. Y., Arbiser, J. L., Saxena, N. K., et al. (2015). Honokiol abrogates leptin-induced tumor progression by inhibiting Wnt1-MTA1- $\beta$-catenin signaling axis in a microRNA-34a dependent manner. Oncotarget 6, 16396-16410. doi: 10.18632/oncotarget. 3844

Batista, P. J., and Chang, H. Y. (2013). Long noncoding RNAs: cellular address codes in development and disease. Cell 152, 1298-1307. doi: 10.1016/j.cell.2013.02.012

Baur, J. A., Pearson, K. J., Price, N. L., Jamieson, H. A., Lerin, C., Kalra, A., et al. (2006). Resveratrol improves health and survival of mice on a high-calorie diet. Nature 444, 337-342. doi: 10.1038/nature05354

Bian, H., Shan, H., and Chen, T. (2017). Resveratrol ameliorates hypoxia/ischemiainduced brain injury in the neonatal rat via the miR-96/Bax axis. Childs. Nerv. Syst. 33, 1937-1945. doi: 10.1007/s00381-017-3509-8

Bijkerk, R., Au, Y. W., Stam, W., Duijs, J. M. G. J., Koudijs, A., Lievers, E., et al. (2019). Long non-coding RNAs rian and miat mediate myofibroblast formation in kidney fibrosis. Front. Pharmacol. 10:215. doi: 10.3389/fphar.2019.00215

Bittencourt, M. I., Cader, S. A., Araújo, D. V., Salles, A. L. F., Albuquerque, F. N., Spineti, P. P. M., et al. (2019). Role of myocardial fibrosis in hypertrophic cardiomyopathy: a systematic review and updated meta-analysis of risk markers for sudden death. Arq. Bras. Cardiol. 112, 281-289. doi: $10.5935 /$ abc. 20190045

Boyle, E. A., Li, Y. I., and Pritchard, J. K. (2017). An expanded view of complex traits: from polygenic to omnigenic. Cell 169, 1177-1186. doi: 10.1016/j.cell.2017.05.038

Bradamante, S., Barenghi, L., and Villa, A. (2004). Cardiovascular protective effects of resveratrol. Cardiovas. Drug Rev. 22, 169-188. doi: 10.1111/j.1527-3466.2004.tb00139.x

Cao, H., Yu, H., Feng, Y., Chen, L., and Liang, F. (2017). Curcumin inhibits prostate cancer by targeting PGK1 in the FOXD3/miR-143 axis. Cancer Chemother. Pharmacol. 79, 985-994. doi: 10.1007/s00280-017-3301-1

Chai, F. N., Ma, W. Y., Zhang, J., Xu, H. S., Li, Y. F., Zhou, Q. D., et al. (2018). Coptisine from Rhizoma coptidis exerts an anti-cancer effect on hepatocellular carcinoma by up-regulating miR-122. Biomed. Pharmacother. 103, 1002-1011. doi: 10.1016/j.biopha.2018.04.052

Chan, L. Y., Kwok, H. H., Chan, R. W., Peiris, M. J., Mak, N. K., Wong, R. N., et al. (2011). Dual functions of ginsenosides in protecting human endothelial cells against influenza H9N2-induced inflammation and apoptosis. J. Ethnopharmacol. 137, 1542-1546. doi: 10.1016/j.jep.2011.08.022

Chen, C. Y., Chen, C. C., Shieh, T. M., Hsueh, C., Wang, S. H., Leu, Y. L., et al. (2018). Corylin suppresses hepatocellular carcinoma progression via the inhibition of epithelial-mesenchymal transition, mediated by long noncoding RNA GAS5. Int. J. Mol. Sci. 19:380. doi: 10.3390/ijms19020380

Chen, F. Y., Bi, L., Qian, L., Gao, J., Jiang, Y. C., and Chen, W. P. (2016). Identification of multidrug resistance gene MDR1 associated microRNA of salvianolic acid a reversal in lung cancer. Chin. J. Chin. Mater. Med. 41, 3279-3284. doi: 10.4268/cjcmm20161726

Chen, M., Ni, Y., Duan, H., Qiu, Y., Guo, C., Jiao, Y., et al. (2008). Mass spectrometry-based metabolic profiling of rat urine associated with general toxicity induced by the multiglycoside of Tripterygium wilfordii Hook. f. Chem. Res. Toxicol. 21, 288-294. doi: 10.1021/tx7002905

\section{FUNDING}

This study was supported by the National Natural Science Foundation of China (No. 81673847; No. 81473561).

Chen, Q., Qin, R., Fang, Y., and Li, H. (2015). Berberine sensitizes human ovarian cancer cells to cisplatin through miR-93/PTEN/Akt signaling pathway. Cell. Physiol. Biochem. 36, 956-965. doi: 10.1159/000430270

Chen, T., Guo, Z. P., Jiao, X. Y., Zhang, Y. H., Li, J. Y., and Liu, H. J. (2011). Protective effects of peoniflorin against hydrogen peroxide-induced oxidative stress in human umbilical vein endothelial cells. Can. J. Physiol. Pharmacol. 89, 445-453. doi: 10.1139/y11-034

Chen, T., Guo, Z. P., Wang, L., Qin, S., Cao, N., Li, M. M., et al. (2013). Paeoniflorin suppresses vascular damage and the expression of E-selectin and ICAM-1 in a mouse model of cutaneous Arthus reaction. Exp. Dermatol. 22, 453-457. doi: 10.1111/exd.12174

Chen, Y., Zhu, L., Yang, X., Wei, C., Chen, C., He, Y., et al. (2017). Ailanthone induces G2/M cell cycle arrest and apoptosis of SGC7901 human gastric cancer cells. Mol. Med. Rep. 16, 6821-6827. doi: 10.3892/mmr.2017.7491

Chen, Z. Z., Zhang, X. D., Chen, Y., and Wu, Y. B. (2017). The role of circulating miR-146a in patients with rheumatoid arthritis treated by Tripterygium wilfordii Hook f. Medicine 96:e6775. doi: 10.1097/MD.0000000000006775

Cheng, J., Chen, T., Li, P., Wen, J., Pang, N., Zhang, L., et al. (2018). Sodium tanshinone IIA sulfonate prevents lipopolysaccharide-induced inflammation via suppressing nuclear factor-кB signaling pathway in human umbilical vein endothelial cells. Can. J. Physiol. Pharmacol. 96, 26-31. doi: 10.1139/cjpp-2017-0023

Cheng, Y., Wang, L., Tang, M., Yin, M., Cui, Y., Liang, H., et al. (2013). Effects of puerarin on cardiac differentiation and ventricular specialization of murine embryonic stem cells. Cell Physiol. Biochem. 32, 789-800. doi: 10.1159/000354480

Choi, H. R., Nam, K. M., Lee, H. S., Yang, S. H., Kim, Y. S., Lee, J., et al. (2016). Phlorizin, an active ingredient of eleutherococcus senticosus, increases proliferative potential of keratinocytes with inhibition of MiR135b and increased expression of type IV collagen. Oxid. Med. Cell. Longev. 2016:3859721. doi: 10.1155/2016/3859721

Clark, A. M., El-Feraly, F. S., and Li, W. S. (1981). Antimicrobial activity of phenolic constituents of magnolia grandiflora L. J. Pharm. Sci. 70, 951-952. doi: $10.1002 /$ jps.2600700833

de Magalhães, J. P., and Passos, J. F. (2018). Stress, cell senescence and organismal ageing. Mech. Age. Dev. 170, 2-9. doi: 10.1016/j.mad.2017.07.001

Douglas, C. C., Johnson, S. A., and Arjmandi, B. H. (2013). Soy and its isoflavones: the truth behind the science in breast cancer. Anticancer Agents Med. Chem. 13, 1178-1187. doi: 10.2174/18715206113139990320

Fan, G., Jiang, X., Wu, X., Fordjour, P. A., Miao, L., Zhang, H., et al. (2016). Anti-inflammatory activity of tanshinone IIA in LPS-Stimulated RAW264.7 macrophages via miRNAs and TLR4-NF-кB pathway. Inflammation 39, 375-384. doi: 10.1007/s10753-015-0259-1

Feng, J., Li, S., and Chen, H. (2016). Tanshinone IIA inhibits myocardial remodeling induced by pressure overload via suppressing oxidative stress and inflammation: Possible role of silent information regulator 1. Eur. J. Pharmacol. 791, 632-639. doi: 10.1016/j.ejphar.2016.09.041

Feng, M., Luo, X., Gu, C., Li, Y., Zhu, X., and Fei, J. (2015). Systematic analysis of berberine-induced signaling pathway between miRNA clusters and mRNAs and identification of mir-99a $\sim 125 \mathrm{~b}$ cluster function by seedtargeting inhibitors in multiple myeloma (MM) cells. RNA Biol. 12, 82-91. doi: 10.1080/15476286.2015.1017219

Fulda, S., and Vucic, D. (2012). Targeting IAP proteins for therapeutic intervention in cancer. Nat. Rev. Drug. Discov. 11:109. doi: 10.1038/nrd3627

Gao, H., Yang, X., Gu, X., and Zhu, Y. Z. (2016). Synthesis and biological evaluation of the codrug of Leonurine and Aspirin as cardioprotective agents. Bioorg. Med. Chem. Lett. 26, 4650-4654 doi: 10.1016/j.bmcl.2016. 08.058 
Gao, X., Dai, M., Li, Q., Wang, Z., Lu, Y., and Song, Z. (2017). HMGA2 regulates lung cancer proliferation and metastasis. Thorac. Cancer 8, 501-510. doi: 10.1111/1759-7714.12476

Garvin, S., Ollinger, K., and Dabrosin, C. (2006). Resveratrol induces apoptosis and inhibits angiogenesis in human breast cancer xenografts in vivo. Cancer Lett. 231, 113-122. doi: 10.1016/j.canlet.2005.01.031

Goto, H., Shimada, Y., Akechi, Y., Kohta, K., Hattori, M., and Terasawa, K. (1996). Endothelium-dependent vasodilator effect of extract prepared from the roots of Paeonia lactiflora on isolated rat aorta. Planta. Med. 62, 436-439. doi: 10.1055/s-2006-957934

Gu, Y., Körbel, C., Scheuer, C., Nenicu, A., Menger, M. D., and Laschke, M. W. (2016). Tubeimoside-1 suppresses tumor angiogenesis by stimulation of proteasomal VEGFR2 and Tie2 degradation in a non-small cell lung cancer xenograft model. Oncotarget 7, 5258-5272. doi: 10.18632/oncotarget.6676

Gui, Z., Li, S., Liu, X., Xu, B., and Xu, J. (2015). Oridonin alters the expression profiles of microRNAs in BxPC-3 human pancreatic cancer cells. BMC Complement. Altern. Med. 15:117. doi: 10.1186/s12906-015-0640-5

Guo, H., Xu, Y., and Fu, Q. (2015). Curcumin inhibits growth of prostate carcinoma via miR-208-mediated CDKN1A activation. Tumour. Biol. 36, 8511-8517. doi: 10.1007/s13277-015-3592-y

Guo, J., Li, W., Shi, H., Xie, X., Li, L., Tang, H., et al. (2013). Synergistic effects of curcumin with emodin against the proliferation and invasion of breast cancer cells through upregulation of miR-34a. Mol. Cell. Biochem. 382, 103-111. doi: 10.1007/s11010-013-1723-6

Guo, Y., Zhou, L. Y., You, J. L., and Xue, B. Y. (2015). Expression of long non-coding RNA AK125910 in liver cancer cell apoptosis undergoing curcumin regulation. J. Nanjing Univ. Trad. Chin. Med. 31, 254-257. doi: 10.14148/j.issn.1672-0482.2015.0254

Guyton, J. R. (2006). Benefit versus risk in statin treatment. Am. J. Cardiol. 97, 95C-97C. doi: 10.1016/j.amjcard.2005.12.016

Han, Y., Qiu, H., Pei, X., Fan, Y., Tian, H., and Geng, J. (2018). Low-dose sinapic acid abates the pyroptosis of macrophages by downregulation of IncRNAMALAT1 in rats with diabetic atherosclerosis. J. Cardiovasc. Pharmacol. 71, 104-112. doi: 10.1097/FJC.0000000000000550

Harrington, R. A. (2017). Targeting inflammation in coronary artery disease. N. Engl. J. Med. 377, 1197-1198. doi: 10.1056/NEJMe1709904

Hong, M., Wang, N., Tan, H. Y., Tsao, S. W., and Feng, Y. (2015). microRNAs and Chinese medicinal herbs: New possibilities in cancer therapy. Cancer (Basel). 7, 1643-1657. doi: 10.3390/cancers7030855

Hu, P. F., Chen, W. P., Bao, J. P., and Wu, L. D. (2018). Paeoniflorin inhibits IL- $1 \beta$-induced chondrocyte apoptosis by regulating the $\mathrm{Bax} / \mathrm{Bcl}-2 /$ caspase- 3 signaling pathway. Mol. Med. Rep. 17, 6194-6200. doi: 10.3892/mmr.2018. 8631

Hu, Y., Wen, Q., Liang, W., Kang, T., Ren, L., Zhang, N., et al. (2013). Osthole reverses beta-amyloid peptide cytotoxicity on neural cells by enhancing cyclic AMP response element-binding protein phosphorylation. Biol. Pharm. Bull. 36, 1950-1958. doi: 10.1248/bpb.b13-00561

Huang, C., and $\mathrm{Hu}, \mathrm{G}$. (2018). Shikonin suppresses proliferation and induces apoptosis in endometrioid endometrial cancer cells via modulating miR-106b/PTEN/AKT/mTOR signaling pathway. Biosci. Rep. 38:BSR20171546. doi: 10.1042/BSR20171546

Huang, C., Liu, H., Gong, X. L., Wu, L. Y., and Wen, B. (2017). Effect of evodiamine and berberine on the interaction between DNMTs and target microRNAs during malignant transformation of the colon by TGF- $\beta 1$. Oncol. Rep. 37, 1637-1645. doi: 10.3892/or.2017.5379

Huang, L., Zhao, H., Huang, B., Zheng, C., Peng, W., and Qin, L. (2011). Acanthopanax senticosus: review of botany, chemistry and pharmacology. Pharmazie 66, 83-97. doi: 10.1002/chin.201125219

Huang, Z., Huang, Q., Ji, L., Wang, Y., Qi, X., Liu, L., et al. (2016). Epigenetic regulation of active Chinese herbal components for cancer prevention and treatment: a follow-up review. Pharmacol. Res. 114, 1-12. doi: 10.1016/j.phrs.2016.09.023

Hung, Y. L., Fang, S. H., Wang, S. C., Cheng, W. C., Liu, P. L., Su, C. C., et al. (2017). Corylin protects LPS-induced sepsis and attenuates LPS- induced inflammatory response. Sci. Rep. 7:46299. doi: 10.1038/srep 46299

Ji, Q., Liu, X., Fu, X., Zhang, L., Sui, H., Zhou, L., et al. (2013). Resveratrol inhibits invasion and metastasis of colorectal cancer cells via
MALAT1 mediated Wnt/ $\beta$-catenin signal pathway. PLoS. ONE 8:e78700. doi: 10.1371/journal.pone.0078700

Jiang, M., Guo, L. P., Zhou, W. Y., Li, J., and Wang, J. (2008). Effect of salvianolic acid a on ICAM-1 expression after Hypoxia/Reoxygenation injury in brain microvascular endothelial cells. Tianjin J. Tradit. Chin. Med. 25, 406-407.

Jiang, T., Ren, K., Chen, Q., Li, H., Yao, R., Hu, H., et al. (2017). Leonurine prevents atherosclerosis via promoting the expression of ABCA1 and ABCG1 in a Ppar $\gamma /$ Lxr $\alpha$ signaling pathway-dependent manner. Cell Physiol. Biochem. 43, 1703-1717. doi: 10.1159/000484031

Jiang, Y., Jia, X., and Xia, Y. (2019). Risk factors with the development of infection with tigecycline- and carbapenem-resistant Enterobacter cloacae. Infect. Drug Resist. 12, 667-674. doi: 10.2147/IDR.S189941

Jiang, Z., Yang, Y., Yang, Y., Zhang, Y., Yue, Z., Pan, Z., et al. (2017). Ginsenoside $\mathrm{Rg} 3$ attenuates cisplatin resistance in lung cancer by downregulating PD-L1 and resuming immune. Biomed. Pharmacother. 96, 378-383. doi: 10.1016/j.biopha.2017.09.129

Jin, H., Qiao, F., Wang, Y., Xu, Y., and Shang, Y. (2015). Curcumin inhibits cell proliferation and induces apoptosis of human non-small cell lung cancer cells through the upregulation of miR-192-5p and suppression of PI3K/Akt signaling pathway. Oncol. Rep. 34, 2782-2789. doi: 10.3892/or.2015.4258

Kalra, N., Roy, P., Prasad, S., and Shukla, Y. (2008). Resveratrol induces apoptosis involving mitochondrial pathways in mouse skin tumorigenesis. Life Sci. 82, 348-358. doi: 10.1016/j.lfs.2007.11.006

Kang, N., Zhang, J. H., Qiu, F., Tashiro, S., Onodera, S., and Ikejima, T. (2010). Inhibition of EGFR signaling augments oridonin-induced apoptosis in human laryngeal cancer cells via enhancing oxidative stress coincident with activation of both the intrinsic and extrinsic apoptotic pathways. Cancer Lett. 294, 147-158. doi: 10.1016/j.canlet.2010.01.032

Karimi Dermani F., Saidijam, M., Amini, R., Mahdavinezhad, A., Heydari, K., and Najafi, R. (2017). Resveratrol inhibits proliferation, invasion, and epithelialmesenchymal transition by increasing miR-200c expression in HCT-116 colorectal cancer cells. J. Cell. Biochem. 118, 1547-1555. doi: 10.1002/jcb.25816

Khosravi, A. R., and Erle, D. J. (2016). Chitin-induced airway epithelial cell innate immune responses are inhibited by carvacrol/thymol. PLOS ONE. 11:e0159459. doi: 10.1371/journal.pone.0159459

Kim, Y. J., Lim, H. S., Lee, J., and Jeong, S. J. (2016). Quantitative analysis of psoralea corylifolia linne and its neuroprotective and anti-neuroinflammatory effects in HT22 hippocampal cells and BV-2 microglia. Molecules 21:1076. doi: 10.3390/molecules 21081076

Kong, L., Li, X., Wang, H., He, G., and Tang, A. (2018). Calycosin inhibits nasopharyngeal carcinoma cells by influencing EWSAT1 expression to regulate the TRAF6-related pathways. Biomed. Pharmacother. 106, 342-348. doi: 10.1016/j.biopha.2018.06.143

Kou, X., Liu, X., Chen, X., Li, J., Yang, X., Fan, J., et al. (2016). Ampelopsin attenuates brain aging of D-gal-induced rats through miR-34amediated SIRT1/mTOR signal pathway. Oncotarget 7, 74484-74495. doi: 10.18632/oncotarget.12811

Lagouge, M., Argmann, C., Gerhart-Hines, Z., Meziane, H., Lerin, C., Daussin, F., et al. (2006). Resveratrol improves mitochondrial function and protects against metabolic disease by activating SIRT1 and PGC-1 $\alpha$. Cell 127, 1109-1122. doi: 10.1016/j.cell.2006.11.013

Lai, X. H., Lei, Y., Yang, J., and Xiu, C. K. (2018). Effect of microRNA34a /SIRT1/p53 signal pathway on notoginsenoside R1 delaying vascular endothelial cell senescence. Chin. J. Chin. Mater. Med. 43, 577-584. doi: 10.19540/j.cnki.cjcmm.20180110.001

Lelli, D., Pedone, C., and Sahebkar, A. (2017). Curcumin and treatment of melanoma: The potential role of microRNAs. Biomed. Pharmacother. 88, 832-834. doi: 10.1016/j.biopha.2017.01.078

Li, B., Peng, L., Zhang, J. H., Fu, W. Z., Wang, Y. W., and Huang, C. P. (2014). A study of anti-fatigue and anti-hypoxia enhanced by Rhodiola rosea L. in mice. Food Sci. Technol. 39, 67-70. doi: 10.13684/j.cnki.spkj.2014.08.016

Li, C. H., Tang, S. C., Wong, C. H., Wang, Y., Jiang, J. D., and Chen, Y. (2018). Berberine induces miR-373 expression in hepatocytes to inactivate hepatic steatosis associated AKT-S6 kinase pathway. Eur. J. Pharmacol. 825, 107-118. doi: 10.1016/j.ejphar.2018.02.035

Li, J., Jiang, K., and Zhao, F. (2015). Icariin regulates the proliferation and apoptosis of human ovarian cancer cells through microRNA-21 by targeting PTEN, RECK and Bcl-2. Oncol. Rep. 33, 2829-2836. doi: 10.3892/or.2015.3891 
Li, S. G., Shi, Q. W., Yuan, L. Y., Qin, L. P., Wang, Y., Miao, Y. Q., et al. (2018). C-Myc-dependent repression of two oncogenic miRNA clusters contributes to triptolide-induced cell death in hepatocellular carcinoma cells. J. Exp. Clin. Cancer. Res. 37:51. doi: 10.1186/s13046-018-0698-2

Li, W., Qi, Z., Wei, Z., Liu, S., Wang, P., Chen, Y., et al. (2015). Paeoniflorin inhibits proliferation and induces apoptosis of human glioma cells via microRNA-16 upregulation and matrix metalloproteinase-9 downregulation. Mol. Med. Rep. 12, 2735-2740. doi: 10.3892/mmr.2015.3718

Li, W., Yang, W., Liu, Y., Chen, S, Y., Chin, S., Qi, X., et al. (2017). MicroRNA378 enhances inhibitory effect of curcumin on glioblastoma. Oncotarget 8, 73938-73946. doi: 10.18632/oncotarget.17881

Li, X., Zang, A., Jia, Y., Zhang, J., Fan, W., Feng, J., et al. (2016). Triptolide reduces proliferation and enhances apoptosis of human non-small cell lung cancer cells through PTEN by targeting miR-21. Mol. Med. Rep. 13, 2763-2768. doi: 10.3892/mmr.2016.4844

Li, Y., Kong, D., Ahmad, A., Bao, B., Dyson, G., and Sarkar, F. H. (2012). Epigenetic deregulation of miR-29a and miR-1256 by isoflavone contributes to the inhibition of prostate cancer cell growth and invasion. Epigenetics 7, 940-949. doi: 10.4161/epi.21236

Li, Q., Liu, M., Fu, R., Cao, Q., Wang, Y., Han, S., et al. (2018). Alteration of circulating innate lymphoid cells in patients with atherosclerotic cerebral infarction. Am. J. Transl. Res. 10, 4322-4330.

Liang, S. M., Lu, Y. J., Ko, B. S., Jan, Y. J., Shyue, S. K., Yet, S. F., et al. (2017). Cordycepin disrupts leukemia association with mesenchymal stromal cells and eliminates leukemia stem cell activity. Sci. Rep. 7:43930. doi: 10.1038/srep43930

Liu, D., Li, G., Liu, D., and Cao, Y. (2001). Effects of tetrandrine on the synthesis of collagen and scar-derived fibroblast DNA. Zhonghua. Shao. Shang. Za. Zhi. 17, 222-224. doi: 10.3760/cma.j.issn.1009-2587.2001.04.010

Liu, J., Li, D., Sun, X., Wang, Y., Xiao, Q., and Chen, A. (2016). Icariine restores LPS-induced bone loss by downregulating miR-34c level. Inflammation 39, 1764-1770. doi: 10.1007/s10753-016-0411-6

Liu, J., Qu, C. B., Xue, Y. X., Li, Z., Wang, P., and Liu, Y. H. (2015). MiR-143 enhances the antitumor activity of shikonin by targeting BAG3 expression in human glioblastoma stem cells. Biochem. Biophys. Res. Commun. 468, 105-112. doi: 10.1016/j.bbrc.2015.10.153

Liu, L., Ning, B., Cui, J., Zhang, T., and Chen, Y. (2017). miR-29c is implicated in the cardioprotective activity of Panax notoginseng saponins against isoproterenol-induced myocardial fibrogenesis. J. Ethnopharmacol. 198, 1-4. doi: 10.1016/j.jep.2016.12.036

Liu, S. C., Chiu, C. P., Tsai, C. H., Hung, C. Y., Li, T. M., Wu, Y. C., et al. (2017). Soya-cerebroside, an extract of Cordyceps militaris, suppresses monocyte migration and prevents cartilage degradation in inflammatory animal models. Sci. Rep. 7:43205. doi: 10.1038/srep43205

Liu, T., Chi, H., Chen, J., Chen, C., Huang, Y., Xi, H., et al. (2017). Curcumin suppresses proliferation and in vitro invasion of human prostate cancer stem cells by ceRNA effect of miR-145 and lncRNA-ROR. Gene 631, 29-38. doi: 10.1016/j.gene.2017.08.008

Liu, W. L., Chang, J. M., Chong, I. W., Hung, Y. L., Chen, Y. H., Huang, W. T., et al. (2017). Curcumin inhibits LIN-28A through the activation of miRNA-98 in the lung cancer cell Line A549. Molecules 22:929. doi: 10.3390/molecules22060929

Lu, B., Sheng, Y., Zhang, J., Zheng, Z., and Ji, L. (2016). The altered microRNA profile in andrographolide-induced inhibition of hepatoma tumor growth. Gene 588, 124-133. doi: 10.1016/j.gene.2016.05.012

Lu, L. N., Liang, Z. W., Luo, J. H., Li, L., Yuan, L., Yang, H., et al. (2019). Effect of leonurine on p38 MAPK signaling pathway and miRNA-1 in cardiomyocyte hypertrophy induced by Ang II. Chin. J. Exp. Trad. Med. Form. 25, 81-86. doi: 10.13422/j.cnki.syfjx.20190337

Lu, Y., Wang, J., Liu, L., Yu, L., Zhao, N., Zhou, X., et al. (2017). Curcumin increases the sensitivity of Paclitaxel-resistant NSCLC cells to Paclitaxel through microRNA-30c-mediated MTA1 reduction. Tumour. Biol. 39:1010428317698353. doi: 10.1177/1010428317698353

Luo, H., Gu, C., Liu, C., Wang, Y., Wang, H., and Li, Y. (2018). Plasma metabolic profiling analysis of Strychnos nux-vomica Linn. and Tripterygium wilfordii Hook F-induced renal toxicity using metabolomics coupled with UPLC/Q-TOF-MS. Toxicol. Res. 7, 1153-1163. doi: 10.1039/C8TX $00115 \mathrm{D}$

Luo, X., Gu, J., Zhu, R., Feng, M., Zhu, X., Li, Y., et al. (2014). Integrative analysis of differential miRNA and functional study of miR-21 by seed-targeting inhibition in multiple myeloma cells in response to berberine. BMC Syst. Biol. 8:82. doi: 10.1186/1752-0509-8-82

Ma, C., Wang, Y., Shen, A., and Cai, W. (2017). Resveratrol upregulates SOCS1 production by lipopolysaccharide-stimulated RAW264.7 macrophages by inhibiting miR-155. Int. J. Mol. Med. 39, 231-237. doi: 10.3892/ijmm.2016.2802

Ma, F., Liu, F., Ding, L., You, M., Yue, H., Zhou, Y., et al. (2017). Antiinflammatory effects of curcumin are associated with down regulating microRNA-155 in LPS-treated macrophages and mice. Pharm. Biol. 55, 1263-1273. doi: 10.1080/13880209.2017.1297838

Ma, J., Fang, B., Zeng, F., Pang, H., Zhang, J., Shi, Y., et al. (2014). Curcumin inhibits cell growth and invasion through up-regulation of miR-7 in pancreatic cancer cells. Toxicol. Lett. 231, 82-91. doi: 10.1016/j.toxlet.2014.09.014

Mahajan, G. J., Vallender, E. J., Garrett, M. R., Challagundla, L., Overholser, J. C., Jurjus, G., et al. (2018). Altered neuro-inflammatory gene expression in hippocampus in major depressive disorder. Prog. Neuropsychopharmacol. Biol. Psych. 82, 177-186. doi: 10.1016/j.pnpbp.2017.11.017

Mao, Z. J., Weng, S. Y., Wang, L., and Chai, K. F. (2018). Mechanism study of berberine in regulating miR-29a-3p and insulin receptor pathway in IR-HepG2 cells. Chin. J. Tradit. Chin. Med. Pharm. 33, 5559-5562.

Marasa, B. S., Srikantan, S., Martindale, J. L., Kim, M. M., Lee, E. K., Gorospe, M., et al. (2010). MicroRNA profiling in human diploid fibroblasts uncovers miR-519 role in replicative senescence. Aging 2, 333-343. doi: 10.18632/aging.100159

Marcais, A., Blevins, R., Graumann, J., Feytout, A., Dharmalingam, G., Carroll, T., et al. (2014). MicroRNA- mediated regulation of mTOR complex components facilitates discrimination between activation and anergy in CD4 T cells. J. Exp. Med. 211, 2281-2295. doi: 10.1084/jem.20132059

Memczak, S., Jens, M., Elefsinioti, A., Torti, F., Krueger, J., Rybak, A., et al. (2013). Circular RNAs are a large class of animal RNAs with regulatory potency. Nature 495, 333-338. doi: 10.1038/nature11928

Mirzaei, H., Masoudifar, A., Sahebkar, A., Zare, N., Sadri Nahand, J., Rashidi, B. (2018). MicroRNA: A novel target of curcumin in cancer therapy. J. Cell. Physiol. 233, 3004-3015. doi: 10.1002/jcp.26055

Miyoshi, T., Uchino, K., Yoshida, H., Motomura, K., Takeda, N., Matsuura, Y., et al. (2015). Long-term viral shedding and viral genome mutation in norovirus infection. J. Med. Virol. 87, 1872-1880. doi: 10.1002/jmv.24242

Mohamed, M. S., Bishr, M. K., Almutairi, F. M., and Ali, A. G. (2017). Inhibitors of apoptosis: clinical implications in cancer. Apoptosis 22, 1487-1509. doi: 10.1007/s10495-017-1429-4

Mohammadi, A., Mansoori, B., and Baradaran, B. (2017). Regulation of miRNAs by herbal medicine: An emerging field in cancer therapies. Biomed. Pharmacother. 86, 262-270. doi: 10.1016/j.biopha.2016.12.023

Nagalingam, R. S.,Sundaresan, N. R., Gupta, M. P., Geenen, D. L., Solaro, R. J., and Gupta, M. (2013). A cardiac-enriched microRNA, miR-378, blocks cardiac hypertrophy by targeting Ras signaling. J. Biol. Chem. 288, 11216-11232. doi: 10.1074/jbc.M112.442384

Ning, P., Peng, Y., Liu, D. W., Hu, Y. H., Liu, Y., and Liu, D. M. (2016). Tetrandrine induces microRNA differential expression in human hypertrophic scar fibroblasts in vitro. Genet. Mol. Res. 15:gmr.15017288. doi: 10.4238/gmr.15017288

Pan, Y., Qian, J. X., Lu, S. Q., Chen, J. W., Zhao, X. D., Jiang, Y., et al. (2017). Protective effects of tanshinone IIA sodium sulfonate on ischemia-reperfusioninduced myocardial injury in rats. Iran. J. Basic. Med. Sci. 20, 308-315. doi: 10.22038/ijbms.2017.8361

Peng, S., Yi, Z., and Liu, M. (2017). Ailanthone: a new potential drug for castrationresistant prostate cancer. Chin. J. Cancer 36:25. doi: 10.1186/s40880-017-0194-7

Pothineni, N. V. K., Subramany, S., Kuriakose, K., Shirazi, L. F., Romeo, F., Shah, P. K., et al. (2017). Infections, atherosclerosis, and coronary heart disease. Eur. Heart J. 38, 3195-3201. doi: 10.1093/eurheartj/ehx362

Qu, S., Shen, Y., Wang, M., Wang, X., and Yang, Y. (2018). Suppression of miR-21 and miR-155 of macrophage by cinnamaldehyde ameliorates ulcerative colitis. Int. Immunopharmacol. 67, 22-34. doi: 10.1016/j.intimp.2018.11.045

Ramakumari, N., Indumathi, B., Katkam, S. K., and Kutala, V. K. (2018). Impact of pharmacogenetics on statin-induced myopathy in South-Indian subjects. Ind. Heart J. 70, S120-S125. doi: 10.1016/j.ihj.2018.07.009

Reno, T. A., Kim, J. Y., and Raz, D. J. (2015). Triptolide inhibits lung cancer cell migration, invasion, and metastasis. Ann. Thorac. Surg. 100, 1817-1824. doi: 10.1016/j.athoracsur.2015.05.074 
Robinson, D., Humbert, M., Buhl, R., Cruz, A. A., Inoue, H., Korom, S., et al. (2017). Revisiting Type 2-high and Type 2-low airway inflammation in asthma: current knowledge and therapeutic implications. Clin. Exp. Allergy 47, 161-175. doi: $10.1111 /$ cea. 12880

Roy, P., Madan, E., Kalra, N., Nigam, N., George, J., Ray, R. S., et al. (2009). Resveratrol enhances ultraviolet B-induced cell death through nuclear factor$\kappa \mathrm{B}$ pathway in human epidermoid carcinoma A431 cells. Biochem. Biophys. Res. Commun. 384, 215-220. doi: 10.1016/j.bbrc.2009.04.100

Saini, S., Arora, S., Majid, S., Shahryari, V., Chen, Y., Deng, G., et al. (2011). Curcumin modulates microRNA-203-mediated regulation of the Src-Akt axis in bladder cancer. Cancer Prev. Res. 4:1698709. doi: 10.1158/1940-6207.CAPR-11-0267

Sana, J., Faltejskova, P., Svoboda, M., and Slaby, O. (2012). Novel classes of non-coding RNAs and cancer. J. Transl. Med. 10:103. doi: 10.1186/1479-5876-10-103

Sayed, A. S., Gomaa, I. E. O., Bader, M., and El Sayed, N. S. E. D. (2018). Role of 3-Acetyl-11-Keto-Beta-Boswellic acid in counteracting LPS-induced neuroinflammation via modulation of miRNA-155. Mol. Neurobiol. 55, 5798-5808. doi: 10.1007/s12035-017-0801-2

Shah, S. K., and Gecys, G. T. (2006). Prednisone-induced osteoporosis: an overlooked and undertreated adverse effect. J. Am. Osteopath. Assoc. 106, 653-657. doi: 10.1016/S0168-9452(99)00147-8

Shan, H., Li, X., Pan, Z., Zhang, L., Cai, B., Zhang, Y., et al. (2009). Tanshinone IIA protects against sudden cardiac death induced by lethal arrhythmias via repression of microRNA-1. Br. J. Pharmacol. 158, 1227-1235. doi: 10.1111/j.1476-5381.2009.00377.x

Shang, Q., Xu, H., and Huang, L. (2012). Tanshinone IIA: a promising natural cardioprotective agent. Evid. Based. Complement. Alternat. Med. 2012, 716459. doi: 10.1155/2012/716459

Shi, H., Bi, H., Sun, X., Dong, H., Jiang, Y., Mu, H., et al. (2017). Antitumor effects of Tubeimoside-1 in NCI-H1299 cells are mediated by microRNA-126$5 \mathrm{p}$-induced inactivation of VEGF-A/ VEGFR-2/ ERK signaling pathway. Mol. Med. Rep. 17, 4327-4336. doi: 10.3892/mmr.2018.8459

Shin, M. S., Song, J. H., Choi, P., Lee, J. H., Kim, S. Y., Shin, K. S., et al. (2018). Stimulation of innate immune function by Panax ginseng after heat processing. J. Agric. Food. Chem. 66, 4652-4659. doi: 10.1021/acs.jafc.8b00152

Siddiqui, M. Z. (2011). Boswellia serrata, a potential anti-inflammatory agent: an overview. Indian J. Pharm. Sci. 73, 255-261. doi: 10.4103/0250-474X.93507

Song, H., Wang, P., Liu, J., and Wang, C. (2017). Panax notoginseng preparations for unstable angina pectoris: a systematic review and meta-analysis. Phytother. Res. 31, 1162-1172. doi: 10.1002/ptr.5848

$\mathrm{Su}$, Q., Yao, J., and Sheng, C. (2018). Geniposide attenuates LPS-induced injury via up-regulation of miR-145 in H9c2 cells. Inflammation 41, 1229-1237. doi: 10.1007/s10753-018-0769-8

Su, Y. H., Tang, W. C., Cheng, Y. W., Sia, P., Huang, C. C., Lee, Y. C., et al. (2015). Targeting of multiple oncogenic signaling pathways by Hsp90 inhibitor alone or in combination with berberine for treatment of colorectal cancer. Biochim. Biophys. Acta. 1853, 2261-2272. doi: 10.1016/j.bbamcr.2015. 05.012

Sun, Q., Zhang, W., Guo, Y., Li, Z., Chen, X., Wang, Y., et al. (2016). Curcumin inhibits cell growth and induces cell apoptosis through upregulation of miR-33b in gastric cancer. Tumour. Biol. 37, 13177-13184. doi: 10.1007/s13277-016-5221-9

Takagi, A., Kano, M., and Kaga, C. (2015). Possibility of breast cancer prevention: use of soy isoflavones and fermented soy beverage produced using probiotics. Int. J. Mol. Sci. 16, 10907-10920. doi: 10.3390/ijms160510907

Tang, N., Zhang, J., and Du, Y. P. (2010). Curcumin promoted the apoptosis of cisplain-resistant human lung carcinoma cells A549/DDP through down-regulating miR-186*. Chin. J. Lung Cancer 13, 301-306. doi: 10.3779/j.issn.1009-3419.2010.04.06

Tay, Y., Rinn, J., and Pandolfi, P. P. (2014). The multilayered complexity of ceRNA crosstalk and competition. Nature 505, 344-352. doi: 10.1038/nature12986

Tian, F., Yu, C. T., Ye, W. D., and Wang, Q. (2017). Cinnamaldehyde induces cell apoptosis mediated by a novel circular RNA hsa_circ_0043256 in nonsmall cell lung cancer. Biochem. Biophys. Res. Commun. 493, 1260-1266. doi: 10.1016/j.bbrc.2017.09.136

Tian, L., Song, Z., Shao, W., Du, W. W., Zhao, L. R., Zeng, K., et al. (2017). Curcumin represses mouse 3T3-L1 cell adipogenic differentiation via inhibiting
miR-17-5p and stimulating the Wnt signalling pathway effector Tcf7l2. Cell. Death. Dis. 8:e2559. doi: 10.1038/cddis.2016.455

Tili, E., Michaille, J. J., Adair, B., Alder, H., Limagne, E., Taccioli, C., et al. (2010). Resveratrol decreases the levels of miR-155 by upregulating miR663, a microRNA targeting JunB and JunD. Carcinogenesis 31, 1561-1566. doi: $10.1093 /$ carcin/bgq143

Tseng, A., Yang, C. H., Chen, C. H., Chen, C. H., Hsu, S. L., Lee, M. H., et al. (2016). An in vivo molecular response analysis of colorectal cancer treated with Astragalus membranaceus extract. Oncol. Rep. 35, 659-668. doi: 10.3892/or.2015.4441

Tu, Y. (2011). The discovery of artemisinin (qinghaosu) and gifts from Chinese medicine. Nat. Med. 17, 1217-1220. doi: 10.1038/nm.2471

$\mathrm{Tu}, \mathrm{Y}$. (2016). Artemisinin-A gift from traditional Chinese medicine to the world (Nobel Lecture). Angew. Chem. Int. Ed. Engl. 55, 10210-10226. doi: 10.1002/anie.201601967

Wan, Y., Wang, Y., Cui, X. X., Feng, J. Y., Long, J., Liu, Y. F., et al. (2017) Effects of total flavonoids from Astragalus membranaceus (Fisch.) Bunge. on the expression of miRNA378 and miRNA378 in neonatal rat cardiomyocytes infected with Coxsackie B3 virus. Chin. J. Appl. Physiol. 33, 55-57.

Wang, D., Zhang, Y., Lu, J., Wang, Y., Wang, J., Meng, Q., et al. (2016) Cordycepin, a natural antineoplastic agent, induces apoptosis of breast cancer cells via caspase-dependent pathways. Nat. Prod. Commun. 11, 63-68. doi: 10.1177/1934578X1601100119

Wang, G., Dai, F., Yu, K., Jia, Z., Zhang, A., Huang, Q., et al. (2015). Resveratrol inhibits glioma cell growth via targeting oncogenic microRNAs and multiple signaling pathways. Int. J. Oncol. 46, 1739-1747. doi: 10.3892/ijo.2015.2863

Wang, H., Zhou, H., Wang, C. X., Li, Y. S., Xie, H. Y., Luo, J. D., et al. (2012). Paeoniflorin inhibits growth of human colorectal carcinoma HT 29 cells in vitro and in vivo. Food. Chem. Toxicol. 50, 1560-1567. doi: 10.1016/j.fct.2012.01.035

Wang, J., Masika, J., Zhou, J., Wang, J., Zhu, M., Luo, H., et al. (2015). Traditional Chinese medicine baicalin suppresses mESCs proliferation through inhibition of miR-294 expression. Cell Physiol. Biochem. 35, 1868-1876. doi: $10.1159 / 000373997$

Wang, L., Cui, Y., Tang, M., Hu, X., Luo, H., Hescheler, J., et al. (2014). Puerarin facilitates T-tubule development of murine embryonic stem cell-derived cardiomyocytes. Cell. Physiol. Biochem. 34, 383-392. doi: 10.1159/000363007

Wang, L., Zhang, R., Chen, J., Wu, Q., and Kuang, Z. (2017). Baicalin protects against TNF- $\alpha$-Induced injury by down-regulating miR-191a that targets the tight junction protein ZO-1 in IEC-6 cells. Biol. Pharm. Bull. 40, 435-443. doi: 10.1248/bpb.b16-00789

Wang, N., Zhu, M., Wang, X., Tan, H. Y., Tsao, S. W., and Feng, Y. (2014). Berberine-induced tumor suppressor p53 up-regulation gets involved in the regulatory network of MIR-23a in hepatocellular carcinoma. Biochim. Biophys. Acta 1839, 849-857. doi: 10.1016/j.bbagrm.2014.05.027

Wang, Q., Fan, H., Liu, Y., Yin, Z., Cai, H., Liu, J., et al. (2014). Curcumin enhances the radiosensitivity in nasopharyngeal carcinoma cells involving the reversal of differentially expressed long non-coding RNAs. Int. J. Oncol. 44, 858-864. doi: 10.3892/ijo.2013.2237

Wang, S. S., Lv, Y., Xu, X. C., Zuo, Y., Song, Y., Wu, G. P., et al. (2019). Triptonide inhibits human nasopharyngeal carcinoma cell growth via disrupting Lnc-RNA THOR-IGF2BP1 signaling. Cancer Lett. 28, 13-24. doi: 10.1016/j.canlet.2018.11.028

Wang, Y., Deng, L., Zhong, H., Jiang, X., and Chen, J. (2011). Natural plant extract tubeimoside I promotes apoptosis-mediated cell death in cultured human hepatoma (HepG2) cells. Biol. Pharm. Bull. 34, 831-838. doi: 10.1248/bpb.34.831

Wang, Y., Dong, X., Li, Z., Wang, W., Tian, J., and Chen, J. (2014). Downregulated RASD1 and upregulated miR-375 are involved in protective effects of calycosin on cerebral ischemia/reperfusion rats. J. Neurol. Sci. 339, 144-148. doi: 10.1016/j.jns.2014.02.002

Wang, J., Teng, F., Duan, L., Liu, Y. M., and Chen, G. (2017). Intervention effect of Xuesaitong on apoptosis of endothelial cells by miRNA-146. Chin. J. Exp. Trad. Med. Form. 23, 6-10. doi: 10.13422/j.cnki.syfjx.20171 90006

Watanabe, S., Kawamoto, S., Ohtani, N., and Hara, E. (2017). Impact of senescence-associated secretory phenotype and its potential as a therapeutic target for senescence-associated diseases. Cancer Sci. 108, 563-569. doi: $10.1111 /$ cas. 13184 
Wei, Y., Li, M., Cui, S., Wang, D., Zhang, C. Y., Zen, K., et al. (2016). Shikonin inhibits the proliferation of human breast cancer cells by reducing TumorDerived exosomes. Molecules 21:777. doi: 10.3390/molecules21060777

Wei, Y. P., Wang, X. H., Liu, G., Zhang, J. F., Yang, Y. X., Zhang, J., et al. (2018). Matrine exerts inhibitory effects in melanoma through the regulation of miR-19b-3p/PTEN. Int. J. Oncol. 53, 791-800. doi: 10.3892/ijo.2018.4414

Wilcock, D. M., Gharkholonarehe, N., Van Nostrand, W. E., Davis, J., Vitek, M. P., and Colton, C. A. (2009). Amyloid reduction by amyloid-beta vaccination also reduces mouse tau pathology and protects from neuron loss in two mouse models of Alzheimer's disease. J. Neurosci. 29, 7957-7965. doi: 10.1523/JNEUROSCI.1339-09.2009

Wu, F., and Cui, L. (2017). Resveratrol suppresses melanoma by inhibiting NFкB/miR-221 and inducing TFG expression. Arch. Dermatol. Res. 309, 823-831. doi: $10.1007 /$ s00403-017-1784-6

Wu, H., Liu, Q., Cai, T., Chen, Y. D., and Wang, Z. F. (2015). Induction of microRNA-146a is involved in curcumin-mediated enhancement of temozolomide cytotoxicity against human glioblastoma. Mol. Med. Rep. 12, 5461-5466. doi: 10.3892/mmr.2015.4087

Wu, J. J., Liu, J., Chen, E. B., Wang, J. J., Cao, L., Narayan, N., et al. (2013). Increased mammalian lifespan and a segmental and tissue-specific slowing of aging after genetic reduction of mTOR expression. Cell Rep. 4, 913-920. doi: 10.1016/j.celrep.2013.07.030

Wu, Y. Y., Huang, X. M., Liu, J., Cha, Y., Chen, Z. P., Wang, F., et al. (2016). Functional study of the upregulation of miRNA-27a and miRNA27b in 3T3-L1 cells in response to berberine. Mol. Med. Rep. 14, 2725-2731. doi: $10.3892 / \mathrm{mmr} .2016 .5545$

Xiao, H. H., Jiao, Y. N., Yan, Y. H., Li, H. Y., and Yang, J. X. (2017). Osthole reduced $A \beta$ synthesis by up-regulating miRNA-107 in neurons transfected with APP_(595/596) gene. Chin. Pharmacol. Bull. 33, 1079-1085. doi: 10.3969/j.issn.1001-1978.2017.08.009

Xuan, Y., Gao, Y., Huang, H., Wang, X., Cai, Y., and Luan, Q. X. (2017). Tanshinone IIA attenuates atherosclerosis in apolipoprotein $\mathrm{E}$ knockout mice infected with porphyromonas gingivalis. Inflammation 40, 1631-1642. doi: $10.1007 /$ s10753-017-0603-8

Yang, C., Zhao, L., Yuan, W., and Wen, J. (2017). Cordycepin induces apoptotic cell death and inhibits cell migration in renal cell carcinoma via regulation of microRNA-21 and PTEN phosphatase. Biomed. Res. 38, 313-320. doi: $10.2220 /$ biomedres. 38.313

Yang, D., Tan, S., Yang, Z., Jiang, P., Qin, C., Yuan, Q., et al. (2018). Dihydromyricetin attenuates TNF- $\alpha$-induced endothelial dysfunction through miR-21-mediated DDAH1/ADMA/NO signal pathway. Biomed. Res. Int. 2018:1047810. doi: 10.1155/2018/1047810

Yang, L. H., Li, D. X., Su, Y. L., and Su, X. L. (2016). Inhibitory effect of berberine on human melanoma A375 cells. Chin. J. Dermatovenereol. 30, 1123-1126. doi: $10.13735 /$ j.cjdv.1001-7089.201605119

Yang, P., Sun, D., and Jiang, F. (2018). Ailanthone promotes human vestibular schwannoma cell apoptosis and autophagy by downregulation of miR-21. Oncol. Res. 26, 941-948. doi: 10.3727/096504018X15149775533331

Yang, Q., Wang, P., Cui, J., Wang, W., Chen, Y., and Zhang, T. (2016). Panax notoginseng saponins attenuate lung cancer growth in part through modulating the level of Met/miR-222 axis. J. Ethnopharmacol. 193, 255-265. doi: 10.1016/j.jep.2016.08.040

Yang, Q., Wang, X., Cui, J., Wang, P., Xiong, M., Jia, C., et al. (2014). Bidirectional regulation of angiogenesis and miR-18a expression by PNS in the mouse model of tumor complicated by myocardial ischemia. BMC Complement. Altern. Med. 14:183. doi: $10.1186 / 1472-6882-14-183$

Yang, X. Y., Qiang, G. F., Zhang, L., and Du, G. H. (2011). Myocardial protection from ischemia-reperfusion injury by Saivianolic acid A in rats. Chin. Pharmacol. Bull. 27, 1072-1076. doi: 10.3969/j.issn.1001-1978.2011.08.010

Yang, Z. B., Luo, X. J., Ren, K. D., Peng, J. J., Tan, B., Liu, B., et al. (2015). Beneficial effect of magnesium lithospermate $B$ on cerebral ischemia-reperfusion injury in rats involves the regulation of miR-107/glutamate transporter 1 pathway. Eur. J. Pharmacol. 766, 91-98. doi: 10.1016/j.ejphar.2015.09.042

Yang, Z. B., Zhang, Z., Li, T. B., Lou, Z., Li, S. Y., Yang, H., et al. (2014). Up-regulation of brain-enriched miR-107 promotes excitatory neurotoxicity through down-regulation of glutamate transporter-1 expression following ischaemic stroke. Clin. Sci. 127, 679-689. doi: 10.1042/CS20 140084
Yin, Z., Yang, J. H., Ning, R., Liu, Y. J., Feng, M. X., Gu, C. M., et al. (2018). Signal pathways, diseases, and functions associated with the miR-19a/92a cluster and the use of berberine to modulate the expression of this cluster in multiple myeloma cells. J. Biochem. Mol. Toxicol. 32:e22057. doi: 10.1002/jbt.22057

You, H. Y., Xie, X. M., Zhang, W. J., Zhu, H. L., and Jiang, F. Z. (2016). Berberine modulates cisplatin sensitivity of human gastric cancer cells by upregulation of miR-203 in vitro. Cell. Dev. Biol. Anim. 52, 857-863. doi: 10.1007/s11626-016-0044-y

Yu, D. S., Wang, Y. S., Bi, Y. L., Guo, Z. P., Yuan, Y. J., Tong, S. M., et al. (2017). Salvianolic acid a ameliorates the integrity of blood-spinal cord barrier via miR-101/Cul3/Nrf2/HO-1 signaling pathway. Brain Res. 1657, 279-287. doi: 10.1016/j.brainres.2016.12.007

Yu, M. L., Li, S. M., Gao, X., Li, J. G., Xu, H., and Chen, K. J. (2018). Sodium tanshinone II a sulfonate for coronary heart disease: a systematic review of randomized controlled trials. Chin. J. Integr. Med. 24, 1-8. doi: 10.1007/s11655-018-2556-7

Yu, X., Ling, J., Liu, X., Guo, S., Lin, Y., Liu, X., et al. (2017). Cordycepin induces autophagy-mediated c-FLIPL degradation and leads to apoptosis in human non-small cell lung cancer cells. Oncotarget 8, 6691-6699. doi: 10.18632 /oncotarget.14262

Yu, X., Zhang, N., Lin, W., Wang, C., Gu, W., Ling, C., et al. (2018). Regulatory effects of four ginsenoside monomers in humoral immunity of systemic lupus erythematosus. Exp. Ther. Med. 15, 2097-2103. doi: 10.3892/etm.2017.5657

Yuan, X., Wang, J., Tang, X., Li, Y., Xia, P., and Gao, X. (2015). Berberine ameliorates nonalcoholic fatty liver disease by a global modulation of hepatic mRNA and IncRNA expression profiles. J. Transl. Med. 13:24. doi: 10.1186/s12967-015-0383-6

Zhai, Y., Dang, Y., Gao, W., Zhang, Y., Xu, P., Gu, J., et al. (2015). P38 and JNK signal pathways are involved in the regulation of phlorizin against UVBinduced skin damage. Exp. Dermatol. 24, 275-279. doi: 10.1111/exd.12642

Zhang, C., Cai, T., Zeng, X., Cai, D., Chen, Y., Huang, X., et al. (2018). Astragaloside IV reverses MNNG-induced precancerous lesions of gastric carcinoma in rats: regulation on glycolysis through miRNA-34a/LDHA pathway. Phytother. Res. 32, 1364-1372. doi: 10.1002/ptr.6070

Zhang, H., Zhang, L., Zhang, Q., Yang, X., Yu, J., Shun, S., et al. (2011). Puerarin: A novel antagonist to inward rectifier potassium channel (ik1). Mol. Cell. Biochem. 352, 117-123. doi: 10.1007/s11010-0110746-0

Zhang, H., Zheng, J., Lin, J., Chen, J., Yu, Z., Chen, C., et al. (2018b). miR-758 mediates oxLDL-dependent vascular endothelial cell damage by suppressing the succinate receptor SUCNR1. Gene 663, 1-8. doi: 10.1016/j.gene.2018. 04.029

Zhang, H., Zheng, J., Shen, H., Huang, Y., Liu, T., Xi, H., et al. (2018a). Curcumin suppresses in vitro proliferation and invasion of human prostate cancer stem cells by modulating DLK1-DIO3 imprinted gene cluster microRNAs. Genet. Test. Mol. Biomarkers. 22, 43-50. doi: 10.1089/gtmb.2017.0179

Zhang, J., Su, H. L., Wang, Y. Z., Wen, X. L., Jia, B. B., and Mao, G. X. (2017). The miRNA microarray analysis of salidroside's anti-aging function in human embryonic lung fibroblast 2BS cells. Acta Pharmaceutica. Sinica. 52, 550-555. doi: $10.16438 /$ j.0513-4870.2016-1040

Zhang, J. H., and Xiong, Y. A. (2015). Effect of paeonol on rats' ischemic arrhythmia and miRNA-1 expression. Chin. J. Exp. Tradit. Med. Form. 21, 129-132. doi: 10.13422/j.cnki.syfjx.2015050129

Zhang, L., Wu, Y., Li, Y., Xu, C., Li, X., Zhu, D., et al. (2012). Tanshinone IIA improves miR-133 expression through MAPK ERK1/2 pathway in hypoxic cardiac myocytes. Cell. Physiol. Biochem. 30, 843-852. doi: 10.1159/000341462

Zhang, Q., Tan, Y., Zhang, N., and Yao, F. (2015a). Polydatin prevents angiotensin II-induced cardiac hypertrophy and myocardial superoxide generation. Exp. Biol. Med. 240, 1352-1361. doi: 10.1177/1535370214561958

Zhang, Q., Tan, Y., Zhang, N., and Yao, F. (2015b). Polydatin supplementation ameliorates diet-induced development of insulin resistance and hepatic steatosis in rats. Mol. Med. Rep. 11, 603-610. doi: 10.3892/mmr.2014.2708

Zhang, S., Chen, S., Shen, Y., Yang, D., Liu, X., Sun-Chi, A. C., et al. (2006). Puerarin induces angiogenesis in myocardium of rat with myocardial infarction. Biol. Pharm. Bull. 29, 945-950. doi: 10.1248/bpb. 29.945

Zhang, S., Tang, D., Zang, W., Yin, G., Dai, J., Sun, Y. U., et al. (2017). Synergistic inhibitory effect of traditional Chinese medicine astragaloside 
IV and curcumin on tumor growth and angiogenesis in an orthotopic Nude-Mouse model of human hepatocellular carcinoma. Anticancer. Res. 37, 465-473. doi: 10.21873/anticanres.11338

Zhang, X. Y., Tang, X. Y., Ma, L. J., Guo, Y. L., Li, X. S., Zhao, L. M., et al. (2017). Schisandrin B down-regulated lncRNA BCYRN1 expression of airway smooth muscle cells by improving miR-150 expression to inhibit the proliferation and migration of ASMC in asthmatic rats. Cell. Prolif. 50:e12382. doi: $10.1111 /$ cpr.12382

Zhang, Y., Lin, Y., Xiao, L., Feng, E., Wang, W., and Lin, L. (2015). The effects of icariine concentration on osteoclasts bone resorption induced by titanium particles in vitro. Regen. Biomater. 2, 197-202. doi: 10.1093/rb/rbv002

Zhang, Y., Zhang, L., Chu, W., Wang, B., Zhang, J., Zhao, M., et al. (2010). Tanshinone IIA inhibits miR-1 expression through p38 MAPK signal pathway in post-infarction rat cardiomyocytes. Cell. Physiol. Biochem. 26, 991-998. doi: 10.1159/000324012

Zhao, J., Zhang, X., Dong, L., Wen, Y., Zheng, X., Zhang, C., et al. (2015). Cinnamaldehyde inhibits inflammation and brain damage in a mouse model of permanent cerebral ischaemia. Br. J. Pharmacol. 172, 5009-5023. doi: 10.1111/bph.13270

Zhao, L., Liu, C. C., Shi, X. L., and Wang, N. (2016). Inhibitory effect of KyoT2 overexpression on proliferation and migration of airway smooth muscle cells in mice with asthma. Zhongguo Dang Dai Er Ke Za Zhi. 18, 885-890. doi: 10.7499/j.issn.1008-8830.2016.09.019

Zhao, Y. N., Li, W. F., Li, F., Zhang, Z., Dai, Y. D., Xu, A. L., et al. (2013). Resveratrol improves learning and memory in normally aged mice through microRNA-CREB pathway. Biochem. Biophys. Res. Commun. 435, 597-602. doi: 10.1016/j.bbrc.2013.05.025

Zheng, L. Q., Zhang, L., Dong, X. H., and Wang, J. (2013). A review on the pharmacological effects and mechanisms of osthole. Acta Neuropharmacol. 3, 29-35. doi: 10.3969/j.issn.13-1404/R.2013.06.005

Zhou, F. H., Wen, Z. Y., He, Z. H., Li, M., Yin, Q. L., Shi, C. G., et al. (2016). Effect of polydatin on miR-214 expression and liver function in ApoE ${ }^{-/-}$mice. Nan. Fang. Yi. Ke. Da. Xue. Xue. Bao. 36, 763-767. doi: 10.3969/j.issn.1673-4254.2016.06.05

Zhou, H., Bian, D., Jiao, X., Wei, Z., Zhang, H., Xia, Y., et al. (2011). Paeoniflorin protects against lipopolysaccharide-induced acute lung injury in mice by alleviating inflammatory cell infiltration and microvascular permeability. Inflamm. Res. 60, 981-990. doi: 10.1007/s00011-011-0359-9

Zhou, S., Li, J., Xu, H., Zhang, S., Chen, X., Chen, W., et al. (2017). Liposomal curcumin alters chemosensitivity of breast cancer cells to Adriamycin via regulating microRNA expression. Gene 622, 1-12. doi: 10.1016/j.gene.2017.04.026

Zhou, S. Y., Zhang, S. J., Xu, H. Z., and Tang, J. H. (2018). Curcumin-loaded liposome alters chemosensitivity of breast cancer cells to Adriamycin by regulating the expression of MicroRNAs. J. Nanjing Univ. Tradit. Chin. Med. 34, 312-317. doi: 10.14148/j.issn.1672-0482.2018.0312

Zhou, Y., Wang, X., Zhang, J., He, A., Wang, Y. L., Han, K., et al. (2017). Artesunate suppresses the viability and mobility of prostate cancer cells through UCA1, the sponge of miR-184. Oncotarget 8, 18260-18270. doi: 10.18632/oncotarget.15353

Zhu, J., Xu, Y., Ren, G., Hu, X., Wang, C., Yang, Z., et al. (2017). Tanshinone IIA Sodium sulfonate regulates antioxidant system, inflammation, and endothelial dysfunction in atherosclerosis by downregulation of CLIC1. Eur. J. Pharmacol. 815, 427-436. doi: 10.1016/j.ejphar.2017. 09.047

Zhuang, Y., Li, T., Zhuang, Y., Li, Z., Yang, W., Huang, Q., et al. (2019). Involvement of lncR-30245 in myocardial infarction-induced cardiac fibrosis through peroxisome proliferator-activated receptor- $\gamma$-mediated connective tissue growth factor signalling pathway. Can. J. Cardiol. 35, 480-489. doi: 10.1016/j.cjca.2019.02.005

Conflict of Interest Statement: The authors declare that the research was conducted in the absence of any commercial or financial relationships that could be construed as a potential conflict of interest.

Copyright (C) 2019 Dong, Chen, Gao, Liu, Li and Wang. This is an open-access article distributed under the terms of the Creative Commons Attribution License (CC BY). The use, distribution or reproduction in other forums is permitted, provided the original author(s) and the copyright owner(s) are credited and that the original publication in this journal is cited, in accordance with accepted academic practice. No use, distribution or reproduction is permitted which does not comply with these terms. 


\section{APPENDIX}

Chem. 1-43 Chemical formulae of bioactive ingredients from CHMs.<smiles></smiles>

Chem. 1 Berberine

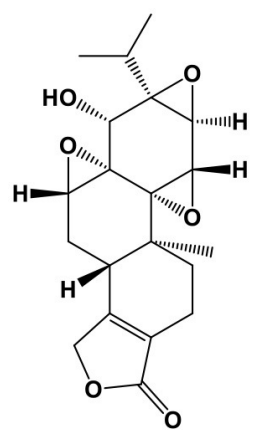

Chem. 3 Triptolide

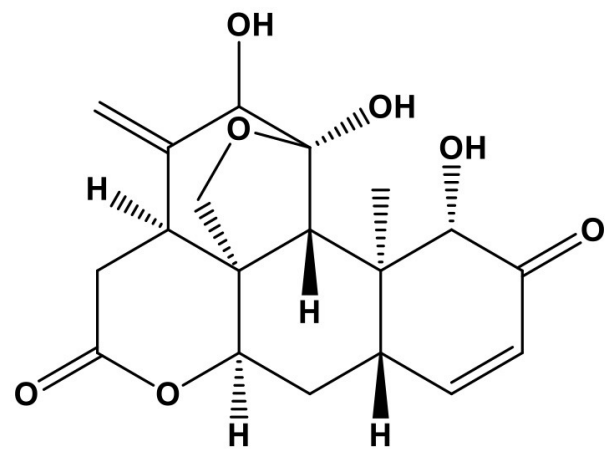

Chem. 5 Ailanthone

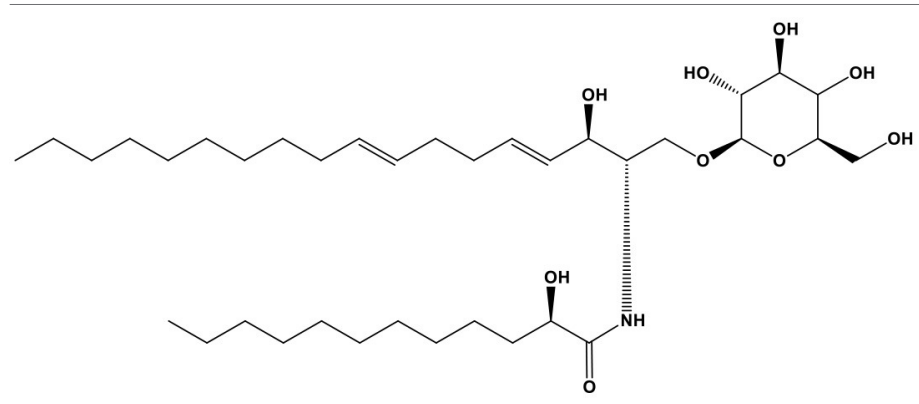

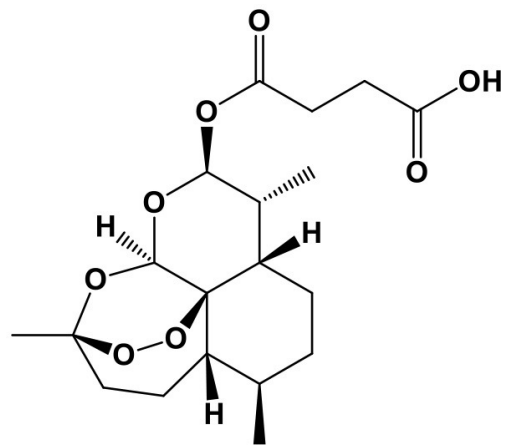

Chem. 2 Artesunate
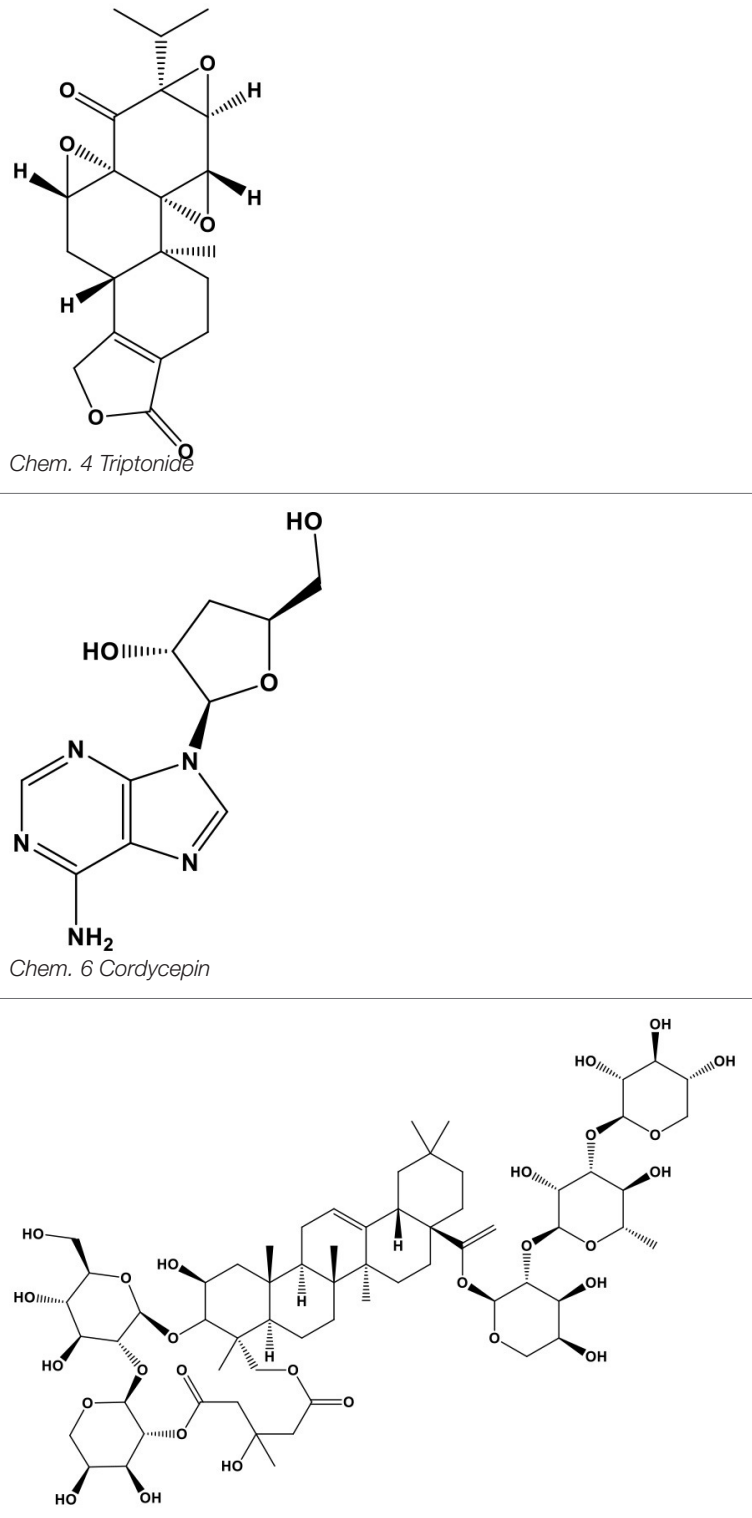

Chem. 8 Tubeimoside I 


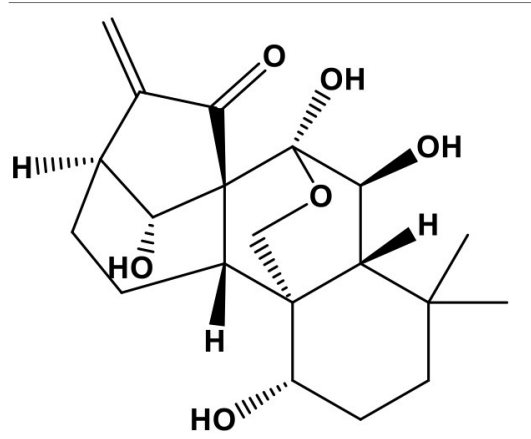

Chem. 9 Oridonin<smiles>CC(C)=CC[C@H](O)C1=CC(=O)c2c(O)ccc(O)c2C1=O</smiles>

Chem. 11 Shikonin<smiles>C=CCc1ccc(O)c(-c2ccc(O)c(CC=C)c2)c1</smiles>

Chem. 13 Honokiol<smiles>Oc1ccc(/C=C/c2cc(O)cc(O)c2)cc1</smiles>

Chem. 15 Resveratrol<smiles>COc1cc(/C=C/C(=O)CC(=O)/C=C/c2ccc(O)c(OC)c2)ccc1O</smiles>

Chem. 10 Curcumin

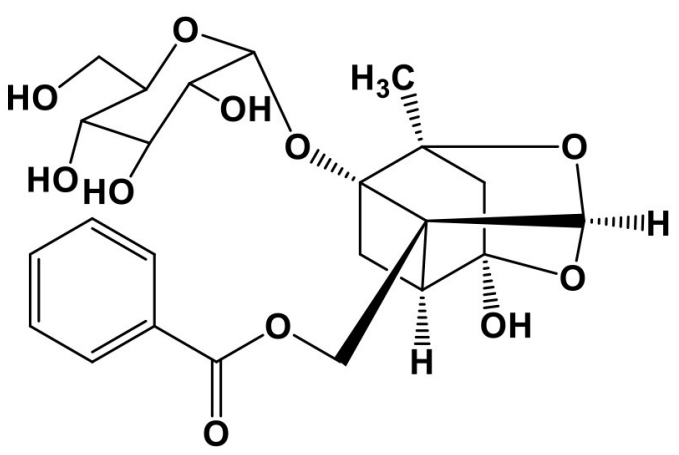

Chem. 12 Paeoniflorin

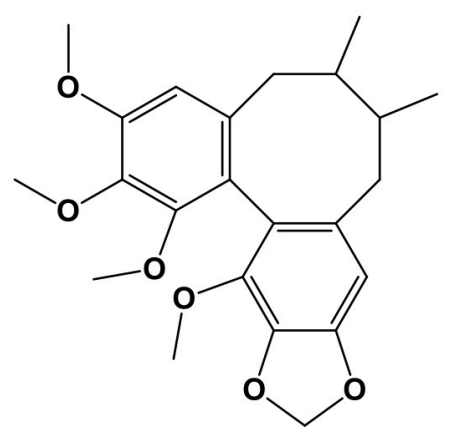

Chem. 14 Schiscandrin B

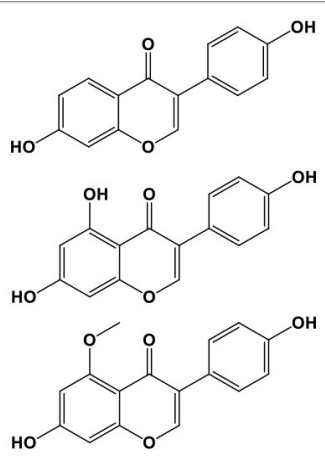

Chem. 16 Soybean isoflavones 


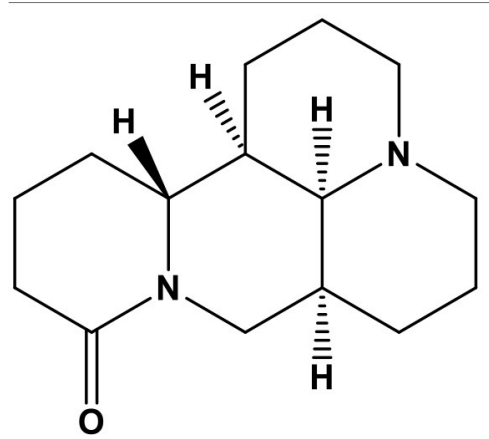

Chem. 17 Matrine<smiles>CC1(C)CCCc2c1ccc1c2C(=O)C(=O)c2ccoc2-1</smiles>

Chem. 19 Tanshinones UA<smiles>CC1(C)C=Cc2cc(-c3coc4cc(O)ccc4c3=O)ccc2O1</smiles>

Chem. 18 Corylin

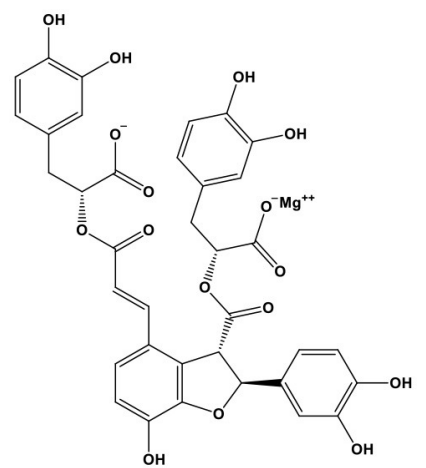

Chem. 20 Magnesium lithospermate B

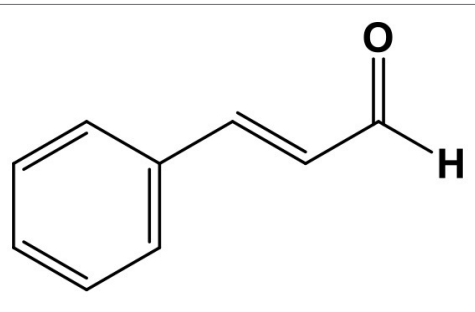

Chem. 22 Cinnamaldehyde

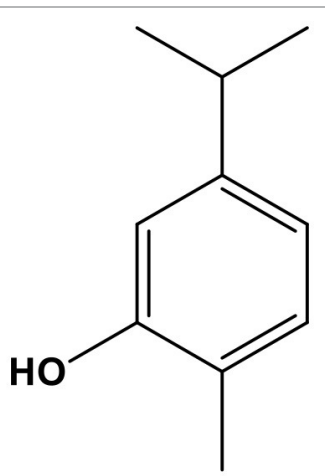

Chem. 24 Carvacrol 


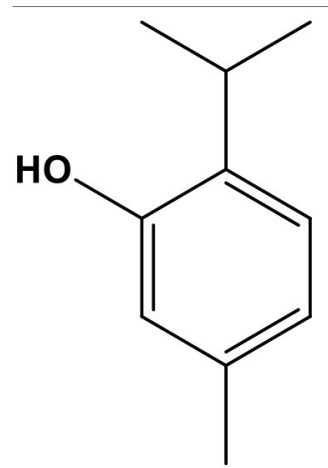

Chem. 25 Thymo

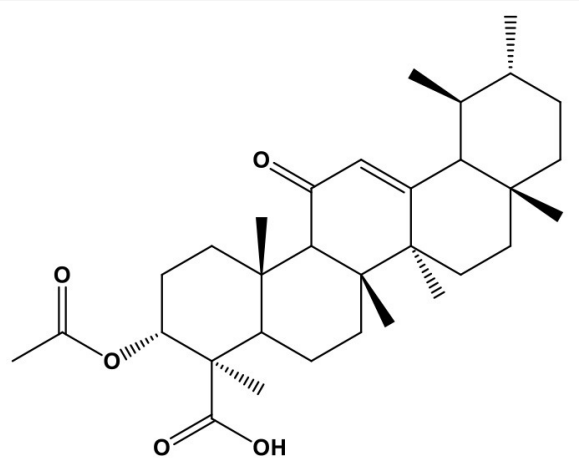

Chem. 26 3-acetyl-11-keto-a-boswellic acid<smiles>OC[C@H]1O[C@@H](Oc2cc(O)cc(/C=C/c3ccc(O)cc3)c2)[C@H](O)[C@@H](O)C1O</smiles>

Chem. 28 Polydatin

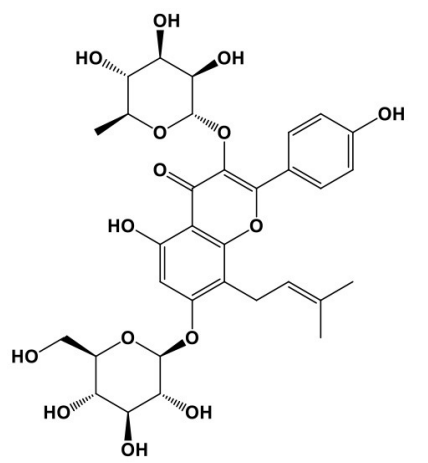

Chem. 30 Icariine

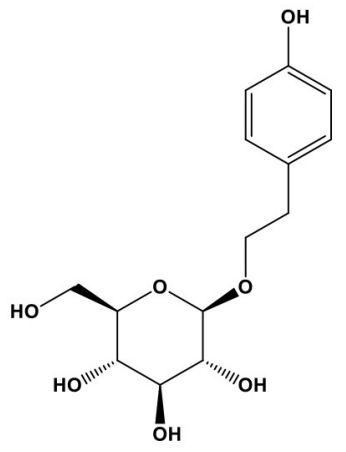

Chem. 32 Salidroside 
<smiles>CCCCCCCCCCCCCC(=O)c1c(O)cc(O)cc1O[C@@H]1O[C@H](CO)[C@@H](O)[C@H](O)[C@H]1O</smiles><smiles>COc1ccc2ccc(=O)oc2c1CC=C(C)CO</smiles>

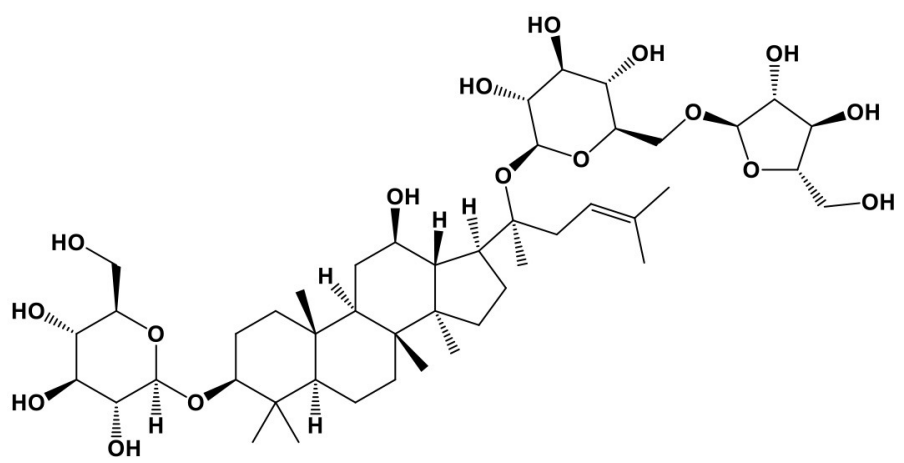

Chem. 35 Panax Notoginseng Saponins<smiles>COc1ccc(C[C@@H]2CCc3cc(OC)c(OC)c(Oc4cc5c(cc4OC)CCN(C)[C@@H]5Cc4ccc(Oc5cc6ccc5CCN(C)[C@@H](c5cccc(OC)c5)C6)cc4)c32)cc1</smiles>

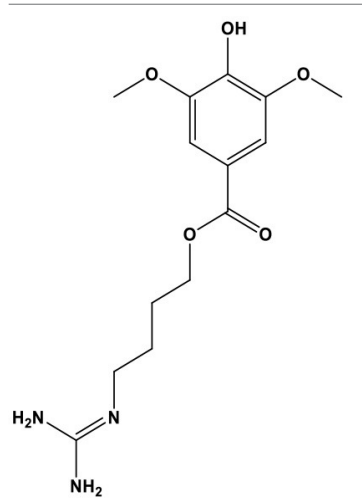

Chem. 37 Leonurine

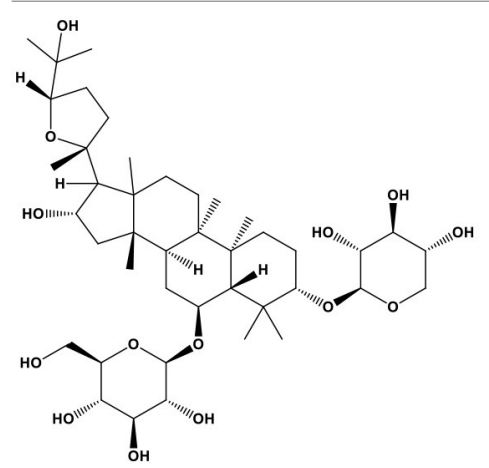

Chem. 39 Astragaloside IV
Chem. 36 Tetrandrine<smiles>COc1ccc(-c2coc3cc(O)ccc3c2=O)cc1O</smiles>

Chem. 38 Calycosin

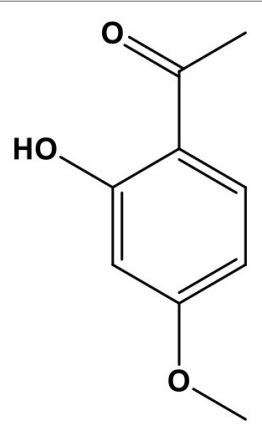

Chem. 40 Paeonol 


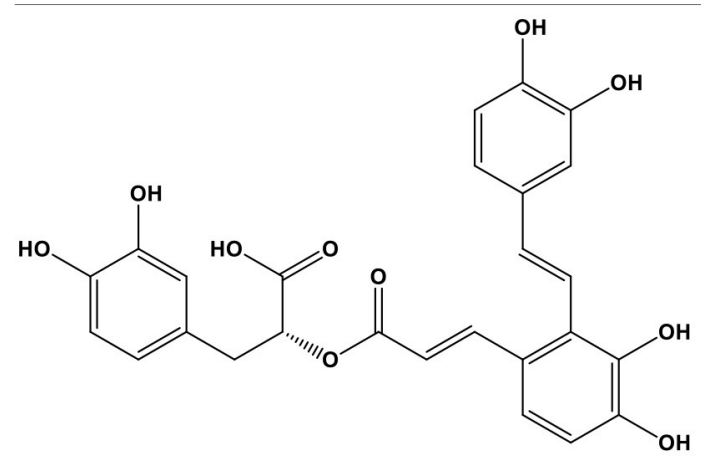

Chem. 41 Salvianolic acid A

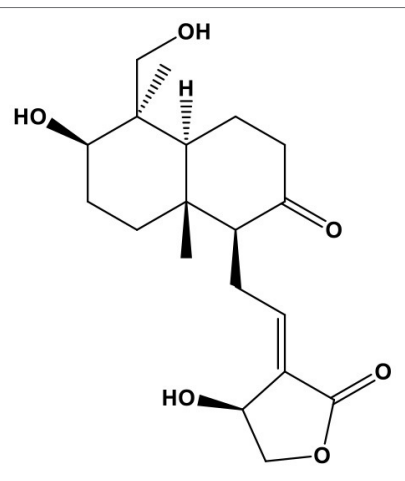

Chem. 42 Andrographolide<smiles>O=c1c(-c2ccc(O)cc2)coc2c(C3O[C@H](CO)[C@@H](O)[C@H](O)[C@H]3O)c(O)ccc12</smiles> 